\title{
2011 SOSORT guidelines: Orthopaedic and Rehabilitation treatment of idiopathic scoliosis during growth
}

Stefano Negrini ${ }^{1,2,3^{*}}$, Angelo G Aulisa ${ }^{4}$, Lorenzo Aulisa ${ }^{5}$, Alin B Circo ${ }^{6}$, Jean Claude de Mauroy ${ }^{7}$, Jacek Durmala ${ }^{8}$, Theodoros B Grivas ${ }^{9}$, Patrick Knott ${ }^{10}$, Tomasz Kotwicki ${ }^{11}$, Toru Maruyama ${ }^{12}$, Silvia Minozzi ${ }^{13}$, Joseph P O'Brien ${ }^{14}$, Dimitris Papadopoulos ${ }^{15}$, Manuel Rigo ${ }^{16}$, Charles H Rivard ${ }^{6}$, Michele Romano ${ }^{3}$, James H Wynne ${ }^{17}$, Monica Villagrasa ${ }^{16}$, Hans-Rudolf Weiss $^{18}$ and Fabio Zaina ${ }^{3}$

\begin{abstract}
Background: The International Scientific Society on Scoliosis Orthopaedic and Rehabilitation Treatment (SOSORT), that produced its first Guidelines in 2005, felt the need to revise them and increase their scientific quality. The aim is to offer to all professionals and their patients an evidence-based updated review of the actual evidence on conservative treatment of idiopathic scoliosis (CTIS).

Methods: All types of professionals (specialty physicians, and allied health professionals) engaged in CTIS have been involved together with a methodologist and a patient representative. A review of all the relevant literature and of the existing Guidelines have been performed. Documents, recommendations, and practical approach flow charts have been developed according to a Delphi procedure. A methodological and practical review has been made, and a final Consensus Session was held during the 2011 Barcelona SOSORT Meeting.

Results: The contents of the document are: methodology; generalities on idiopathic scoliosis; approach to CTIS in different patients, with practical flow-charts; literature review and recommendations on assessment, bracing, physiotherapy, Physiotherapeutic Specific Exercises (PSE) and other CTIS. Sixty-five recommendations have been given, divided in the following topics: Bracing (20 recommendations), PSE to prevent scoliosis progression during growth (8), PSE during brace treatment and surgical therapy (5), Other conservative treatments (3), Respiratory function and exercises (3), Sports activities (6), Assessment (20). No recommendations reached a Strength of Evidence level I; 2 were level II; 7 level III; and 20 level IV; through the Consensus procedure 26 reached level V and 10 level VI. The Strength of Recommendations was Grade A for 13, B for 49 and C for 3; none had grade D.

Conclusion: These Guidelines have been a big effort of SOSORT to paint the actual situation of CTIS, starting from the evidence, and filling all the gray areas using a scientific method. According to results, it is possible to understand the lack of research in general on CTIS. SOSORT invites researchers to join, and clinicians to develop good research strategies to allow in the future to support or refute these recommendations according to new and stronger evidence.
\end{abstract}

\section{Premise \\ Mandate}

The international Scientific Society on Scoliosis Orthopaedic and Rehabilitation Treatment (SOSORT), that produced its first Guidelines during the 2005 Milan

\footnotetext{
* Correspondence: stefano.negrini@med.unibs.it

'Physical and Rehabilitation Medicine, University of Brescia, Italy

Full list of author information is available at the end of the article
}

Meeting, and published them in 2006 in the Journal Scoliosis [1], felt the need to revise them and increase their scientific quality. During the SOSORT 2010 Meeting in Montreal the SOSORT Guidelines Commission was established, coordinated by Stefano Negrini. The Mandate to the Commission was to develop Guidelines methodologically sound and evidence based, giving

\section{Biomed Central}

(C) 2012 Negrini et al; licensee BioMed Central Ltd. This is an Open Access article distributed under the terms of the Creative Commons Attribution License (http://creativecommons.org/licenses/by/2.0), which permits unrestricted use, distribution, and reproduction in any medium, provided the original work is properly cited. 
recommendations according to the strength of the actual evidence.

\section{Commission}

The Commission was open to all SOSORT Members who decided to adhere to the project; it has been decided to include also a methodologist (Silvia Minozzi), while a patient (Joe P O'Brien), member of SOSORT and President of the US National Scoliosis Foundation, has been nominated as an external judge with the patients' perspective.

\section{Content}

The contents of the document of the 2011 SOSORT Guidelines on "Orthopaedic and Rehabilitation Treatment of Idiopathic Scoliosis During Growth" are:

1. Methodology

2. Generalities on idiopathic scoliosis

3. Approach to conservative treatment of idiopathic scoliosis in different patients, with practical flow-charts

4. Literature review and recommendations on assessment, bracing, physiotherapy, Physiotherapeutic Specific Exercises and other conservative treatments

An Appendix (Additional File 1) has been added to give all details the Method used to develop the Guidelines.

\section{Scope, purpose and applications}

The aim of these Guidelines is to offer to all professionals engaged in the conservative treatment of scoliosis an evidence-based updated review of the actual evidence in the field, together with a series of evidencebased recommendations. The multiple gray areas, important for the every day clinical practice, in which it is not possible to give an evidence-based recommendation, have been covered through a formal and explicit consensus methodology, as outlined in the Appendix (Additional File 1), to provide a consensus recommendation.

The Guidelines are meant to apply to all idiopathic scoliosis patients regardless of age. The main clinical questions that they cover are:

- Which assessment of the patient should be performed?

- Which conservative treatment should be provided, and how?

- How and when should bracing be applied?

- How and when should exercises be used?

\section{Development of the Guidelines}

All types of professionals engaged in the conservative treatment of scoliosis have been involved: specialty physicians (orthopaedics, physical and rehabilitation medicine, psychiatry...) and allied health professionals (orthotists, physiotherapists, chiropractors...); a methodologist and a patient representative have been included as well.

Nevertheless, it must be underlined that these Guidelines have been developed by the SOSORT, that is the Society on Scoliosis treatment that is focused exclusively in the conservative approach to scoliosis. The other two international Scientific Societies involved in scoliosis treatment, while considering also the conservative approach, focus mainly either in the surgical treatment (Scoliosis Research Society) or in general research (International Research Society on Spinal Deformities): the SRS and IRSSD have not been involved in this Guidelines development, even if members of these Societies are also members of the SOSORT and participated.

Patients have been involved in the development of the Guidelines through the US National Scoliosis Foundation, representing 25,000 actual scoliosis patients.

\section{Methods}

Methods are outlined in all details in the Appendix (Additional File 1).

For the treatment sections we performed systematic reviews of the literature in February 2011. Medline was searched from its inception, with no language limitations. The search strategies, the selection criteria, and the number of retrieved papers are listed in the individual sections. We also searched: the abstracts of all SOSORT Meetings, from the first one in 2003 to 2010; the personal files and knowledge of all the authors; the papers retrieved with all the other searches listed in these Guidelines; the references sections of all retrieved papers.

To produce the actual Guidelines, a review of the previous ones has been performed: these have been searched through a comprehensive bibliographic search on Medline with the key word "Scoliosis" and "Guidelines" [1-4]. The final documents, recommendations, and practical approach flow charts have been developed according to a Delphi procedure carefully listed in the Appendix (Additional File 1). A methodological and practical review have been made, and a final Consensus Session held during the 2011 Barcelona SOSORT Meeting.

A classical Strength of Evidence (SoE) table has been adopted (Table 1). According to the Italian Guidelines [2], levels V and VI have been added according to the Consensus session held during the SOSORT Meeting. A Strength of Recommendation (SoR) scale has also been used (Table 2), that assumes that each Recommendation should have in the clinical everyday world, balancing all 
Table 1 Strength of Evidence grading used in these Guidelines.

\begin{tabular}{|c|c|c|}
\hline $\begin{array}{l}\text { Strength of } \\
\text { evidence }\end{array}$ & Question & Meaning \\
\hline \multirow[t]{2}{*}{1} & Effectiveness & Multiple Randomized Controlled Trials or Systematic Reviews of such studies \\
\hline & Diagnosis & $\begin{array}{l}\text { Multiple Randomized Controlled Trials, or Cross-sectional Studies with verification by reference (gold) standard, or } \\
\text { Systematic Reviews of such studies }\end{array}$ \\
\hline \multirow[t]{2}{*}{ II } & Effectiveness & One Randomized Controlled Trial \\
\hline & Diagnosis & One Randomized Controlled Trial, or one Cross-sectional Study with verification by reference (gold) standard \\
\hline \multirow[t]{2}{*}{ III } & Effectiveness & Multiple Controlled nonrandomized Studies or Systematic Reviews of such studies \\
\hline & Diagnosis & Multiple Cross-sectional Studies with incomplete \& unbalanced verification with reference (gold) standard \\
\hline \multirow[t]{2}{*}{ IV } & Effectiveness & Other studies \\
\hline & Diagnosis & \\
\hline \multirow[t]{2}{*}{$\mathrm{V}$} & Effectiveness & SOSORT Consensus with more than $90 \%$ of agreement \\
\hline & Diagnosis & \\
\hline \multirow[t]{2}{*}{ VI } & Effectiveness & SOSORT Consensus with 70 to $89 \%$ of agreement \\
\hline & Diagnosis & \\
\hline
\end{tabular}

Questions on Effectiveness (treatment results) and Diagnosis (assessment) have been considered

typical factors involved in this decision (patients, professionals, social). The SoR scale is meant to accompany and complement the Strength of Evidence scale.

\section{Target users of the Guidelines}

Users of these Guidelines are meant to be all professionals involved in the Conservative Treatment of Scoliosis, but they also should serve as reference for patients.

\section{Updates}

Since these Guidelines have been produced in 2011, they will be fully updated by SOSORT between 2016 and 2021. If important changes in practice will intervene before, an update could be decided by the SOSORT Board to be published before that date.

\section{Applicability}

These Guidelines will be published in the Internet Open Access Journal "Scoliosis" http://www.scoliosisjournal. com. This is the most important way to ensure their accessibility to the worldwide community of Scoliosis conservative professionals. Moreover, this will guarantee visibility to the patients. The Consensus process, involving professionals from all over the world, should provide an objective document that a wide variety of interested organizations and third party payers may review to gain insight into the treatment modalities. In the meantime, single national adaptations should eventually be considered. The document in itself should serve ad the basis for these national documents.

Translations in different languages have been already planned, including: French, German, Greek, Italian, Japanese, Polish, Spanish. These translations will be published in the Official SOSORT website: http://www. sosort.org. Moreover, process for National Organizations approvals have been planned, and will be reported in the next Edition of these Guidelines.

\section{General information on idiopathic scoliosis Definitions}

Scoliosis is a general term comprising a heterogeneous group of conditions consisting in changes in the shape and position of the spine, thorax and trunk. The name, believed to have been introduced by Hippocrates (scolios, which means crooked or curved) [5] and used by Galen (scoliosis), means an abnormal lateral spinal curvature. Today, scoliosis is known not to be limited only to the frontal plane, and can be defined as a "threedimensional torsional deformity of the spine and trunk" [6-8]: it causes a lateral curvature in the frontal plane, an axial rotation in the horizontal one, and a

Table 2 Strength of Recommendations grading used in these Guidelines.

\begin{tabular}{ll}
\hline Strength of recommendation & Meaning \\
\hline A & it must be applied widely and to all patients with this specific need \\
\hline C & it is important, but can be applied not to all patients with this specific need \\
\hline D & less important, it can be applied on a voluntary basis \\
\hline
\end{tabular}


disturbance of the sagittal plane normal curvatures, kyphosis and lordosis, usually, but not always, reducing them in direction of a flat back.

"Structural scoliosis", or just scoliosis, must be differentiated from "functional scoliosis", that is a spinal curvature secondary to known extraspinal causes (e.g. shortening of a lower limb or paraspinal muscle tone asymmetry). It is usually partially reduced or completely subsides after the underlying cause is eliminated (e.g. in a recumbent position). Functional scoliosis is not the subject of this paper.

The term Idiopathic Scoliosis was introduced by Kleinberg (1922) (ref), and it is applied to all patients in which it is not possible to find a specific disease causing the deformity; in fact, it appears in apparently healthy children, and can progress in relation to multiple factors during any rapid period of growth. By definition, idiopathic scoliosis is of unknown origin and is probably due to several causes. Etiopathogenetically, the spinal deformity caused by idiopathic scoliosis may be defined as a sign of a syndrome with a multifactorial etiology [9-13]. Nearly always, scoliosis manifests as a solitary deformity, but further investigation may reveal other significant subclinical signs [14,15]. Idiopathic Scoliosis has been described as a torsional deformity of the spine, which combines a translation and rotation of a variable number of vertebrae, changing the 3D geometry of the spine [16-18]. Structural and sometimes a geometrical flat back is seen often, but the geometry of the spine in the lateral radiograph is highly variable. Trunk deformity and back asymmetry correlates with the spinal deformity, but there can be significant discrepancies in some cases [19].

The curvature in the frontal plane (AP radiograph in upright position) is limited by an 'upper end vertebra' and a 'lower end vertebra', taken both as a reference level to measure the Cobb angle. The Scoliosis Research Society (SRS) suggests that the diagnosis is confirmed when the Cobb angle is $10^{\circ}$ or higher and axial rotation can be recognized. Maximum axial rotation is measured at the apical vertebra. However, structural scoliosis can be seen with a Cobb angle under $10^{\circ}$ [20], with a potential for progression. Progression is more common in girls during the growth spurt at puberty and then it is called progressive Idiopathic Scoliosis. When untreated, it may lead to severe trunk deformities, which limit the capacity and functional biomechanics of the chest, exercise capacity, general fitness and ability to work, all factors related with impairment on quality of life.

\section{Epidemiology}

In approximately $20 \%$ of cases, scoliosis is secondary to another pathological process. The remaining $80 \%$ are cases of idiopathic scoliosis. Adolescent idiopathic scoliosis (AIS) with a Cobb angle above $10^{\circ}$ occurs in the general population in a wide range from 0.93 to $12 \%$ [21-38]: two to three percent is the value the most often found in the literature, and it has been suggested that epidemiology changes according to latitude [24,39].

Approximately $10 \%$ of these diagnosed cases require conservative treatment and approximately $0.1-0.3 \%$ require operative correction of the deformity. Progression of AIS is much more frequently seen in females. When the Cobb angle is 10 to $20^{\circ}$, the ratio of affected girls to boys is similar (1.3:1), increasing to $5.4: 1$ for Cobb angles between 20 and $30^{\circ}$, and $7: 1$ for angle values above $30^{\circ}[40,41]$. If the scoliosis angle at completion of growth exceeds a"critical threshold" (most authors assume it to be between $30^{\circ}$ and $50^{\circ}$ ), there is a higher risk of health problems in adult life, decreased quality of life, cosmetic deformity and visible disability, pain and progressive functional limitations [41,42].

\section{Etiology}

The etiopathogenesis of scoliosis has not been elucidated. The causes of scoliosis are being sought in congenital or acquired disorders of vertebral structure. Patients with this type of deformity are usually noted to suffer from such co-existent abnormalities as asymmetrical structure of the brain stem, sensory and balance impairment, disorders of blood platelet and collagen function [3-5]. The role of genetic factors in the development of spinal axial disorders is also emphasised and is confirmed by the tendency of scoliosis to run in families, with researchers suggesting a hereditary disorder of oestrogen receptor structure and function [6].

Numerous authors indicate that the causes of scoliosis are systemic disorders of, among others, mucopolysaccharide and lipoprotein synthesis. In the 1990s a group of researchers under the guidance of Dubousset [7-9] proposed that scoliosis develops as a result of melatonin synthesis disorder. They produced spinal curvatures in chickens via pinealectomy and later ameliorated the melatonin deficiency to find decreased incidence of scoliosis in the animals. Machida reported reduced serum melatonin levels in girls with rapidly progressive idiopathic scoliosis [8]. His finding has been questioned by other authors, who found no differences between melatonin levels in scoliotic girls and those in a healthy control group. Currently, melatonin is attributed only a limited role in scoliosis pathogenesis [10]. The possible role of melatonin in scoliosis etiology is also discussed in connection to age at menarche in different geographic latitudes. [24]

According to more recent studies, calmodulin may disturb melatonin levels. Kindsfater [43] assessed calmodulin levels in order to determine the risk of curve progression. Basing on this hypothesis, melatonin plays a 
secondary role in the spontaneous induction of scoliosis. It is a consequence of interaction with calmodulin, a protein that has receptors for calcium ions and is thus able to influence the contractility of skeletal muscles; it can also be found in blood platelets (its level in platelets was higher in patients with scoliotic progression rates of more than $10^{\circ}$ over 12 months) [11]. Other authors have evaluated the possibility that gene variants of IL-6 and MMPs might be associated with scoliosis and suggests that MMP-3 and IL-6 promoter polymorphisms constitute important factors for the genetic predisposition to scoliosis. Association Between IL-6 [44].

All in all, the etiology of scoliosis has not been fully elucidated $[12,13]$. Based on the variety of opinions on idiopathic scoliosis development, we can assume a multifactorial origin. The opinions presented above are supplementary rather than mutually exclusive. At the same time they explain the complex determinants of and relationships between disorders of spinal development in children and adolescents.

\section{Natural history}

Idiopathic scoliosis (IS) may develop at any time during childhood and adolescence. It is most common in periods of growth spurt-between the ages of 6 and 24 months, 5 and 8 years and 11 and 14 years of life [2]. The rate of development of spinal curvature changes the most rapidly at the beginning of puberty $[23,24]$. According to the Tanner scale, which assesses tertiary sex characteristics, this period corresponds to stage S2 and P2 in girls, and T2 and P2 in boys [25]. The pubertal growth spurt begins with accelerated longitudinal growth of limbs, which causes a temporary disproportion of the body (long limbs and short trunk). Then longitudinal growth is seen in the axial skeleton. It is the period of the most marked progression of IS. After approx. $2 / 3$ of the period of pubescent growth spurt, girls experience menarche, which indicates a slow, gradual decrease in the risk of scoliosis progression:

There is a much lower potential for progression of idiopathic scoliosis after the spinal growth is complete. In adulthood, IS may intensify as a result of progressive osseous deformities and collapsing of the spine. This phenomenon is reported especially in scoliosis that is more severe than $50^{\circ}$, while the risk of progression starts to increase as the curve grows above $30^{\circ}[26,30,31,42]$; less severe idiopathic scoliosis curves often remain stable. Nevertheless, the natural history of adult scoliosis is not well known to date, and it is still possible the progression can have some peak periods [45]. A "de novo" scoliosis has been recognized as a possible form in adulthood [46].

\section{Classifications}

During the years, many different classifications of idiopathic scoliosis have been proposed, but not all of them are either relevant for conservative care, or currently used beyond research purposes. In Table 3 we present the most relevant clinical conservative practices used in clinical practice, with a short discussion that follows.

\section{Chronological}

It has been proposed by James [2], that scoliosis should be classified based on the age of the child at which the deformity was diagnosed (Table 3). This classification is important since the longer the period between diagnosis of scoliosis and completion of growth by the developing child, the greater the risk of developing a more severe and complicated deformity.

Today the general term "Early onset scoliosis" is sometimes used to classify together Infantile and Juvenile scoliosis, but we prefer the James classification, due to the fact that infantile scoliosis has a different prognosis. In fact there are congenital postural scoliosis curves diagnosed in newborns, as a component of a syndrome usually resulting from intrauterine compression caused by malposition of the fetus during pregnancy, and it is an exception to the rule. Such curvatures are not three-plane deformities and usually undergo spontaneous remission. As the range of hip motion is often asymmetrical and the child prefers to rest their head on one side only, exercises and correction of body position are usually employed. Examination usually reveals gradual remission of the curvature in these infants, and such scoliosis curves may thus be categorised as regressive [17].

\section{Angular}

The angle of scoliosis measured on the standing frontal radiograph according to the Cobb method is one of the decisive factors in managing idiopathic scoliosis, and it is directly correlated to all therapeutic decisions. Many different classifications have been proposed based on these angular measurements, but no one system today has widespread validity. Nevertheless, there is an agreement on some thresholds [41,42,47-49]:

- under $10^{\circ}$ of scoliosis, the diagnosis of scoliosis should not be made;

- over $30^{\circ}$ of scoliosis the risk of progression in adulthood increases, as well as the risk of health problems and reduction of quality of life;

- over $50^{\circ}$ there is a consensus that it is almost certain that scoliosis is going to progress in adulthood and cause health problems and reduction of quality of life.

From these thresholds, and taking into account that the recognised measurement error in measuring Cobb angles is $5^{\circ}$ [50-55], very important decisions are made. 
Table 3 Classifications of idiopathic scoliosis.

\begin{tabular}{|c|c|c|c|c|c|c|c|}
\hline \multirow{2}{*}{\multicolumn{2}{|c|}{$\frac{\text { Chronological }}{\text { Age at diagnosis (years.months) }}$}} & \multicolumn{3}{|c|}{ Angular } & \multicolumn{3}{|c|}{ Topographic } \\
\hline & & \multicolumn{3}{|c|}{ Cobb degrees } & & \multicolumn{2}{|c|}{ Apex } \\
\hline & & & & & & from & to \\
\hline Infantile & $0-2.11$ & Low & Low & $5-15$ & Cervical & - & Disc C6-7 \\
\hline Juvenile & 3-9.11 & & Low to moderate & $16-24$ & Cervico-thoracic & C7 & $\mathrm{T} 1$ \\
\hline Adolescent & $10-17.11$ & Moderate & Moderate & $25-34$ & Thoracic & Disc T1-2 & Disc T11-12 \\
\hline \multirow[t]{3}{*}{ Adult } & $18-$ & & Moderate to severe & $35-44$ & Thoraco-lumbar & $\mathrm{T} 12$ & L1 \\
\hline & & Severe & & $45-59$ & Lumbar & Disc L1-2 & - \\
\hline & & Very severe & & 60 or more & & & \\
\hline
\end{tabular}

These include the generally recognised threshold for surgery $\left(45-50^{\circ}\right)$, and the aims of conservative treatment that we will describe below. We propose here a classification useful for conservative physicians and as a way to discuss therapeutic options with the patients (Table 3): it comes from the idea that there is a continuum from one stage to the other, and that the $5^{\circ}$ measurement error must be taken into account.

\section{Topographic}

The remaining most common classifications of idiopathic scoliosis are based on the anatomical site of the spinal deformity in the frontal plane only. A classification developed by Ponseti [56] (based on Schulthess work [57]) distinguishes four major types of scoliosis: thoracic, lumbar, thoraco-lumbar and S-shaped. This classification is the most traditional and used both in conservative treatment and in the pre-operative classification of scoliosis [58], and is reported in Table 3. Two other classification systems of idiopathic scoliosis based on the anatomical site of spinal deformity have been proposed and used in preoperative planning [59-63]. Since these Guidelines deal with conservative treatment, they are not considered here. In the clinical setting of rehabilitation and bracing other classifications have been proposed, but they have not yet become standards [64-68]; moreover, some 3D classifications have been published as well [69-75], but they are far from being validated for clinical everyday application.

\section{Evidence-Based Clinical Practice approach to Idiopathic Scoliosis}

Goals of conservative treatment

General Goals

SOSORT has published in the Scoliosis Journal a Consensus Paper titled "Why do we treat adolescent idiopathic scoliosis? What do we want to obtain and to avoid for our patients. SOSORT 2005 Consensus paper" [42] that can serve as reference for specific insights on this topic. In this paper, the most general goals of treatment can be found (Table 4).
The goals of conservative treatment of idiopathic scoliosis may be divided into two groups: morphological and functional. The first aspect influences aesthetics (that has been proposed as the first goal of treatment by SOSORT experts), while both aspects determine patients' quality of life, psychological well-being, and disability (the second to fourth goals according to SOSORT experts) [42]. The basic objectives of comprehensive conservative treatment of Idiopathic Scoliosis are:

1. to stop curve progression at puberty (or possibly even reduce it),

2. to prevent or treat respiratory dysfunction,

3. to prevent or treat spinal pain syndromes,

4. to improve aesthetics via postural correction,

To stop curve progression at puberty (orpossibly even reduce it) It is believed that it is impossible to fully eradicate idiopathic scoliosis with conservative treatment techniques available at present. It is possible and usually sufficient to prevent further progression, even if recent research papers conducted according to the SRS criteria

Table 4 Goals of treatment according to the SOSORT Consensus paper [42].

\begin{tabular}{ccc}
\hline Rank & Aim & $\begin{array}{c}\text { Percentage of } \\
\text { responders }\end{array}$ \\
\hline 1 & Esthetics & $100 \%$ \\
2 & Quality of life & $91 \%$ \\
3 & Disability & $91 \%$ \\
4 & Back Pain & $87 \%$ \\
5 & Psychological well-being & $84 \%$ \\
6 & Progression in adulthood & $84 \%$ \\
7 & Breathing function & $84 \%$ \\
8 & Scoliosis Cobb degrees & $84 \%$ \\
9 & Need of further treatments in & $81 \%$ \\
& adulthood & \\
\hline
\end{tabular}

Only the goals that reached $80 \%$ of agreement are listed here, starting from the most important. The column "Percentage of responders" refers to those that considered each outcome relevant during the Consensus Conference. 
have shown that it is also possible to obtain some amount of curve correction [76-79].

To prevent or treat respiratory dysfunctions The morphological aspect of the deformity is closely related to the functional aspect. Depending on its degree and location, the curvature affects respiratory function. The most prominent changes within the respiratory system are produced by curvatures of the thoracic spine.

To prevent or treat spinal pain syndromes Scoliotic adults suffer from spinal pain, which they experience more frequently than non-scoliotic adults. Statistically significant differences are already noted in people between 20 and 30 years of age. In a follow-up study of over 40 years duration, three-fold higher prevalence of chronic pain-related complaints and over twenty-fold higher incidence of severe and darting pain in a group of people with untreated idiopathic scoliosis compared to a control group. The occurrence of pain-related complaints is probably multifactorial in origin [80-87].

To improve the appearance via postural correction Quality of life is significantly affected by aesthetic sensation and acceptance of one's appearance. Therefore, visual correction of a scoliosis related external trunk deformity is an important issue in conservative treatment. The assessment of therapeutic outcomes may be based on subjective visual assessment, on specially developed indices of visual evaluation or on parameters of surface topography assessment $[19,88,89]$.

Specific goals of conservative treatment during growth It is possible to define specific goals of conservative treatment of single patients during growth: these can be set according to the starting point ( $\mathrm{x}$-ray before treatment). These goals should be considered as a dynamic tool, to be adapted during treatment according to the change in the deformity, compliance of the patient, therapies proposed and so on. In this respect, we can define the following possibilities:

- Absolute goal: these are the bottom line of conservative treatment. If not anything else, at least these goals should be reached.

- Primary goal: these are the "best possible" goals for patients starting treatment in each specific clinical situation

- Secondary goals: these are the compromise goals that come when it becomes clear that it is not possible to reach the primary goals

According to this approach, SOSORT has reached a Consensus (Strength of Evidence VI-Strength of Recommendation $C$ ) shown in Table 5 . This table has been organized with a minimum and a maximum of primary and secondary goals that can be reached for each clinical situation. The absolute goals are similar for all patients in every clinical situation: avoid fusion surgery. A first approach to this problem, developing a similar scheme, has been proposed in 2007 [90]: these goals were applied in some studies $[77,90]$ and proved to be useful. Accordingly, we propose here these goals of treatment to be applied in clinical studies of conservative treatment of idiopathic scoliosis.

\section{Evidence-Based Clinical Practice approach}

This section is constituted mainly by a Practical Approach Scheme (PAS) (Table 6) that has been prepared through the Consensus Procedure reported in Appendix (Additional File 1). The PAS constitutes a real Evidence Based Clinical Practice Approach to Idiopathic Scoliosis. The Strength of Evidence of PAS is VI, while the Strength of Recommendation is B.

This paper also presents a Strength of Treatments Scheme (STS) (Table 7) that reports all the possible

Table 5 Specific aims of conservative treatment during growth (Strength of Evidence VI-Strength of Recommendation C)

\begin{tabular}{|c|c|c|c|c|}
\hline & & $\begin{array}{l}\text { Adolescent Idiopathic Scoliosis up } \\
\text { to } 45^{\circ}\end{array}$ & $\begin{array}{c}\text { Adolescent Idiopathic Scoliosis } \\
\text { over } 45^{\circ}\end{array}$ & $\begin{array}{l}\text { Infantile and Juvenileldiopathic } \\
\text { Scoliosis }\end{array}$ \\
\hline \multirow{2}{*}{$\begin{array}{l}\text { Radiographic } \\
\text { aims }\end{array}$} & Primary & Below $25^{\circ}$ & Below $35^{\circ}$ & Below $25^{\circ}$ \\
\hline & Secondary & Below $35^{\circ}$ & No progression & Below $50^{\circ}$ \\
\hline Main aims & & & $\begin{array}{c}\text { Avoid surgery } \\
\text { Improve aesthetics and quality of life } \\
\text { Reduce disability and pain }\end{array}$ & \\
\hline
\end{tabular}

Notes and definitions

- Final results depend on the characteristics of the disease (progressive potential) and not only on the quality and quantity of treatment (that rely on the action

of the whole team: physician, orthotist, therapist, family and patient)

- Goals of treatment: what treating team would like to achieve in front of a specific clinical situation.

- Main aims: pursued in all cases beyond Cobb degrees results

- Primary aims: pursued at start of treatment, but not possible in all cases

- Secondary aims: to be pursued if primary aims are not achievable, but also secondary aims are not always possible 
Table 6 Practical Approach Scheme (PAS) for an Evidence Based Clinical Practice approach to Idiopathic Scoliosis (Strength of Evidence VI-Strength of Recommendation B).

\begin{tabular}{|c|c|c|c|c|c|c|c|c|c|c|c|c|}
\hline & & Cobb degrees & $0-10+$ hump & $11-15$ & $16-20$ & $21-25$ & $26-30$ & $31-35$ & $36-40$ & $41-45$ & $46-50$ & Over 50 \\
\hline \multirow{2}{*}{\multicolumn{2}{|c|}{ Infantile }} & Min & Ob6 & Ob6 & Ob3 & SSB & SSB & SSB & SSB & SSB & PTRB & FTRB \\
\hline & & Max & Ob3 & Ob3 & PTRB & FTRB & FTRB & FTRB & FTRB & FTRB & Su & Su \\
\hline \multirow{2}{*}{\multicolumn{2}{|c|}{ Juvenile }} & Min & Ob3 & Ob3 & Ob3 & SSB & SSB & SSB & PTRB & PTRB & PTRB & FTRB \\
\hline & & Max & PSE & PSE & PTRB & FTRB & FTRB & FTRB & FTRB & FTRB & Su & Su \\
\hline \multirow[t]{12}{*}{ Adolescent } & Risser 0 & Min & Ob6 & Ob6 & Ob3 & PSE & PSE & SSB & PTRB & PTRB & PTRB & FTRB \\
\hline & & Max & Ob3 & PSE & PTRB & FTRB & FTRB & FTRB & FTRB & FTRB & Su & Su \\
\hline & Risser 1 & Min & Ob6 & Ob6 & Ob3 & PSE & PSE & SSB & PTRB & PTRB & PTRB & FTRB \\
\hline & & Max & Ob3 & PSE & PTRB & FTRB & FTRB & FTRB & FTRB & FTRB & Su & Su \\
\hline & Risser 2 & Min & Ob8 & Ob6 & Ob3 & PSE & PSE & SSB & SSB & SSB & SSB & FTRB \\
\hline & & Max & Ob6 & PSE & PTRB & FTRB & FTRB & FTRB & FTRB & FTRB & Su & $\mathrm{Su}$ \\
\hline & Risser 3 & Min & Ob12 & Ob6 & Ob6 & Ob6 & PSE & SSB & SSB & SSB & SSB & FTRB \\
\hline & & Max & Ob6 & PSE & PTRB & FTRB & FTRB & FTRB & FTRB & FTRB & Su & Su \\
\hline & Risser 4 & Min & No & Ob6 & Ob6 & Ob6 & Ob6 & Ob6 & Ob6 & Ob6 & SSB & FTRB \\
\hline & & Max & Ob12 & PSE & PTRB & FTRB & FTRB & FTRB & FTRB & FTRB & $\mathrm{Su}$ & Su \\
\hline & Risser 4-5 & Min & No & Ob6 & Ob6 & Ob6 & Ob6 & Ob6 & Ob6 & Ob6 & SSB & FTRB \\
\hline & & Max & Ob12 & PSE & PTRB & FTRB & FTRB & FTRB & FTRB & FTRB & Su & Su \\
\hline \multirow[t]{4}{*}{ Adult } & No pain & Min & No & No & No & No & No & No & No & No & Ob12 & Ob12 \\
\hline & & Max & Ob12 & Ob12 & Ob12 & Ob12 & Ob12 & Ob12 & Ob12 & Ob12 & Ob6 & Ob6 \\
\hline & Chronic Pain & Min & No & PSE & PSE & PSE & PSE & PSE & PSE & PSE & PSE & PSE \\
\hline & & Max & PTRB & PTRB & PTRB & PTRB & PTRB & $\mathrm{Su}$ & $\mathrm{Su}$ & $\mathrm{Su}$ & $\mathrm{Su}$ & $\mathrm{Su}$ \\
\hline \multirow[t]{6}{*}{ Elderly } & No pain & Min & No & No & No & No & No & No & No & No & Ob12 & Ob12 \\
\hline & & Max & Ob12 & Ob12 & Ob12 & Ob12 & Ob12 & Ob12 & Ob12 & Ob12 & Ob6 & Ob6 \\
\hline & Chronic Pain & Min & No & PSE & PSE & PSE & PSE & PSE & PSE & PSE & PSE & PSE \\
\hline & & Max & PTRB & PTRB & PTRB & PTRB & PTRB & PTRB & PTRB & PTRB & Su & Su \\
\hline & Decompensation & Min & No & No & PSE & PSE & PSE & PSE & PSE & PSE & PSE & PSE \\
\hline & & Max & PTRB & PTRB & PTRB & PTRB & PTRB & PTRB & PTRB & PTRB & Su & Su \\
\hline
\end{tabular}

For each single clinical situation reported in any single cell, a minimum and a maximum strength of treatment is listed. The graduation of strength of treatments have been reported in the Strength of Treatments Scheme in Table 8. Consequently, all treatments included between the minimum and maximum can be considered for that specific clinical situation.

Obs 36/12/8/6/4: Observation every 36/12/8/6/4 months; PSE: Physiotherapeutic Specific Exercises; NTRB: Night-time Rigid Bracing (8-12 hours); SIR: Inpatient rehabilitation; SB: Soft bracing; PTRB: Part-Time Rigid Bracing (12-20 hours); FTRB: Full-time Rigid bracing (20-24 hours) or cast; Su: Surgery.

treatments that can be proposed for Idiopathic Scoliosis graduated from the least to the most demanding (both in terms of burden on the patient, and possible efficacy). In addition, the STS is Consensus based (Strength of Evidence V-Strength of Recommendation B). Starting from the STS it is possible to state, for each single clinical situation of the PAS, a minimum and a maximum of possible treatments that could be proposed: consequently all treatments that in the STS are reported between this minimum and maximum can be considered for that specific clinical situation.

The PAS has some main characteristics that constitute its strength and justification:

- It constitutes the way we have chosen to resolve the differences among the various clinicians in their everyday clinical approach, to be able to state what is presumably totally wrong (above the maximum: overtreatment-below the minimum: undertreatment) according to the actual conservative treatment knowledge.

- It reports a real everyday approach, since all clinicians usually chose from quite a wide panel of choices when treating a single patient; the final decision comes after discussion with the patient, and weighting of the various risk factors involved in the clinical situation. In fact, the PAS has been developed looking at the "Step by Step" Sibilla's theory [78,91-94]: for each single patient it is mandatory to chose the correct step of treatment, where the most efficacious is also the most demanding. Accordingly, coming to a wrong decision means facing one of the 
Table 7 Strength of Treatments Scheme (STS) (Strength of Evidence V-Strength of Recommendation B): it reports all the possible treatments that can be proposed for Idiopathic Scoliosis graduated from the less to the most demanding (both in terms of burden on the patient, and possible efficacy).

\begin{tabular}{|c|c|c|c|}
\hline Min & Treatment & Abb & Notes \\
\hline 0 & Nothing & No & \\
\hline 1 & Observation every 36 months & Ob36 & - Observation is clinical evaluation and not x-ray everytime \\
\hline 2 & Observation every 12 months & Ob12 & $\begin{array}{l}\text { - X-rays are usually performed once every two clinical evaluations, unless otherwise justified in the } \\
\text { opinion of a clinician specialized in conservative treatment of spinal deformities }\end{array}$ \\
\hline 3 & Observation every 8 months & Ob8 & \\
\hline 4 & Observation every 6 months & Ob6 & \\
\hline 5 & Observation every 3 months & Ob3 & \\
\hline 6 & $\begin{array}{l}\text { Physiotherapeutic Specific } \\
\text { Exercises (outpatient) }\end{array}$ & PSE & $\begin{array}{l}\text { - The term "Physiotherapeutic" added to "Physiotherapeutic Specific Exercises" does not designate an } \\
\text { exclusive professional proposing the exercises, but the general approach to the patient, that goes } \\
\text { beyond the simple execution of exercises }\end{array}$ \\
\hline 7 & $\begin{array}{l}\text { Night-time Rigid Bracing }(8-12 \\
\text { hours) }\end{array}$ & NTRB & $\begin{array}{l}\text { - According to the actual evidence it is not possible to define which treatment is more effective than } \\
\text { the others between PSE (\#6) and PTRB (\#10), consequently the progressive numbers should be } \\
\text { regarded only as a tool to be applied to the Practical Approach table and not as a classification } \\
\text { approved by SOSORT members }\end{array}$ \\
\hline 8 & Inpatient rehabilitation & SIR & \\
\hline 9 & Specific Soft Bracing & SSB & \\
\hline 10 & $\begin{array}{l}\text { Part-Time Rigid Bracing }(12-20 \\
\text { hours) }\end{array}$ & PTRB & The use of a rigid brace always imply the associated use of Physiotherapeutic Specific Exercises \\
\hline 11 & $\begin{array}{l}\text { Full-time Rigid bracing }(20-24 \\
\text { hours) or cast }\end{array}$ & FTRB & \\
\hline 12 & Surgery & $\mathrm{Su}$ & \\
\hline
\end{tabular}

Min: minimum; Max: maximum; Abb: abbreviation

two main mistakes in conservative treatment of idiopathic scoliosis, overtreatment (too much burden on the patient) or undertreatment (not enough efficacy). - Evidence-Based Clinical Practice is by definition the best integration between the knowledge offered by Evidence-Based Medicine, individual clinical expertise and patients' preferences (Figure 1) [95-98]. Consequently, a single patients treatment by different clinicians, even when faced with the identical clinical situation, can vary either because of the patient preferences or because of the specific expertise of the clinician. This has the final consequence that it will never be possible to state definitively what is the only right approach to a clinical situation, but always a range of situations need to be considered.

In the PAS it has been accepted that single conservative expert physicians treating idiopathic scoliosis patients can move up and down in the same range of treatments, but also to the right or to the left (i.e. changing to a more or less demanding clinical situation, here identified as a column of the PAS), according to the presence or absence of specific risk factors that have been listed at the bottom of PAS.

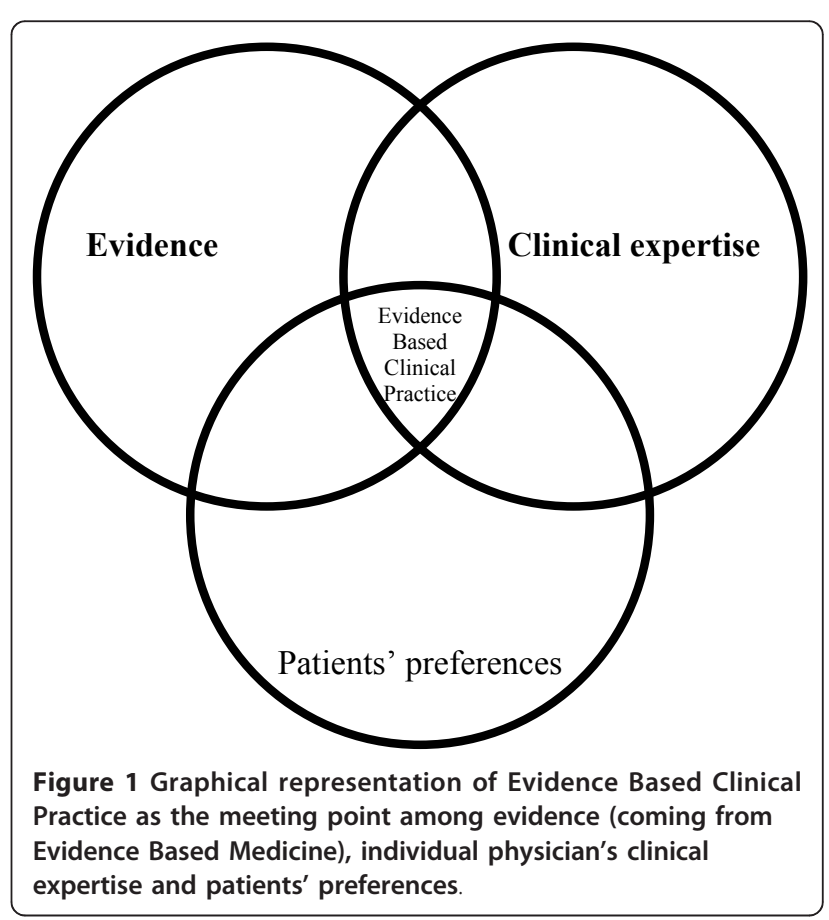


Below we briefly list and describe the different treatments considered in the PAS and listed in the STS. A short description of the various risk factors of progression is provided as well.

\section{Conservative treatments}

All these treatment approaches are listed in the STS (Table 7) and will be presented from the less to the most demanding and possibly efficacious. For more insight it is possible to look at the Brace Technology and Rehabilitation Schools for Scoliosis Series $[99,100]$ published by the journal Scoliosis. Moreover, more specific detail can be found in the Consensus paper on Terminology recently produced by SOSORT [101].

Nothing (No): No treatment is needed.

Observation (Ob). It is the first step of an active approach to idiopathic scoliosis and it is constituted by regular clinical evaluation with a specific follow-up period. Timing of this follow-up can range from 2-3 to 3660 months according to the specific clinical situation. Clinical evaluation does not mean performing $\mathrm{x}$-rays everytime: $x$-rays are usually performed during alternate clinical evaluations.

Physiotherapeutic Specific Exercises (PSE). They include all forms of outpatient physiotherapies that have proven efficacy, that will gradually be published in the Rehabilitation Schools for Scoliosis Series [100] in the journal Scoliosis. They have been listed in the $3^{\text {rd }}$ part of these Guidelines. The frequency of therapeutic sessions depends on the techniques, cooperation and the ability of the patient to carry out the treatment with the assistance of caregivers. At times, it can be conducted daily or several times a week. Long-term outpatient physiotherapy sessions most often take place 2-4 times a week if the patient is willing to co-operate fully. The actual form of exercise depends mainly on the character of the selected therapeutic method.

Special Inpatient Rehabilitation (SIR). This is a special exercise method used on an in-patient basis (hospital department, sanatorium or a similar form of health care). SIR is advised by some schools especially at the beginning of exercise treatment in order to teach the patient and his caregivers how to perform exercises properly.

Bracing: using a brace (a corrective orthosis) for a specified period of time each day to correct scoliosis in three planes (3D). It is used for a period necessary to obtain and maintain the therapeutic outcome. The therapeutic outcome is mainly the halting of scoliosis progression. In some cases it is possible to correct the scoliosis while in others the progression rate can only be slowed down before elective surgery. According to SOSORT, the use of a rigid brace always implys the additional use of exercises when out of the brace.
Bracing includes:

- Night Time Rigid Bracing (8-12 hours per day) (NTRB): wearing a brace mainly in bed.

- Soft Bracing (SB): it includes mainly the SpineCor brace $[102,103]$, but also other similar designs $[104,105]$

- Part Time Rigid Bracing (12-20 hours per day) (PTRB): wearing a brace mainly outside school and in bed.

- Full Time Rigid Bracing (20-24 hours per day) or cast (FTRB): wearing a brace all the time (at school, at home, in bed, etc.). Casts have been included here as well. Casts are used by some schools as the first stage to achieve correction to be maintained afterwards with rigid brace [106-108]; others propose casting only in worst cases $[92,93,109,110]$; a cast is considered a standard approach in infantile scoliosis [111]. Recently, a new brace has been developed that has been claimed to achieve same results as casting $[77,112,113]$.

A common feature of all forms of conservative treatment is the need to actively involve the patient and caregivers [114]. Therefore education, psychotherapy, systematic monitoring of outcomes, assessment of patient's co-operation, and verification and modification of methods in the course of the therapy are crucial elements of conservative treatment. In order to achieve the best possible outcome, conservative treatment should be conducted by an experienced therapeutic team including a physician, a physiotherapist, an orthotist and possibly a psychologist [114]. Support groups and internet forums are also important in conservative treatment.

\section{Prognostic factors}

Using the PAS it is mandatory to include prognostic factors so to move properly between the minimum and maximum strength of treatment. The following factors have been suggested as possible determinants of a higher risk of scoliosis progression: positive family history, laxity of skin and joints (connective tissue defect), flattening of physiological thoracic kyphosis (impedes efficient bracing), angle of trunk rotation exceeding $10^{\circ}$, growth spurt.

Bunnell reported that the risk of progression at the beginning of puberty is $20 \%$ in $10^{\circ}$ scoliosis, $60 \%$ in $20^{\circ}$ scoliosis, and as much as $90 \%$ in $30^{\circ}$ scoliosis $[47,115]$. At the age of peak height growth (13 years of osseous age in girls) the risk of progression is $10 \%, 30 \%$ and $60 \%$, respectively. During the final stage of puberty (at least Risser grade II) the risk of deformity progression becomes considerably lower, falling to $2 \%$ in $10^{\circ}$ scoliosis, $20 \%$ in $20^{\circ}$ scoliosis and $30 \%$ in $30^{\circ}$ scoliosis. The 
prognosis regarding IS progression seems to be more optimistic for boys. [116].

The risk of progression rises with more severe loss of physiological thoracic kyphosis and higher Cobb angles at diagnosis of IS, even if the lateral spine profile of mild $\left(10^{\circ}-20^{\circ}\right)$ scoliotic curves was found to be similar to the lateral spine profile of their healthy controls [117]. Evidence that thoracic hypokyphosis, by facilitating axial rotation, could be viewed as being permissive (a compensatory mechanism), rather than as etiological factor, in IS pathogenesis has also been provided [118].

The pathologic mechanism of progression in an IS curve is nicely described in some recently published papers $[12,119-121]$. The factors which progression is attributed to are: the effect of gravity, the muscle action, the reactive forces causing increased lordosis, the human gait, and the growth induced torsion. The intervertebral disc could be included as an additional morphological factor involved in the progression of an IS curve $[7,100,122]$.

The determination of the risk of idiopathic scoliosis progression has recently been made possible through genetic assessment, with 53 loci identified $[48,123]$. The determination of the polymorphism of selected genes is supposed to facilitate the assignment of a patient to a progressive or stable group [124-126]. A prognostic genetic test has been developed as well [126]. Although these initial results have been promising, great caution is still advised at this stage of the research, while we wait for more stronger proof of efficacy.

Finally, during recent years there have been several prognostic formulas that have been proposed [127-129]. The previous SOSORT guidelines [1] were based on the Lonstein and Carlson factor of progression [129] for the assessment of the risk of idiopathic scoliosis. Since there are no formulas that have been applied in specific studies after their development to verify their real efficacy, we do not apply them in these Guidelines.

Beyond all this discussion, the actual SOSORT Consensus suggests that we consider the following prognostic factors: family history, proven progression, decompensation, short curve, pain, Scoliscore, flat back, and esthetic impact.

\section{Brace treatment Methods}

In February 2011 we performed a search of Medline from its inception, with no language limitations. We used the following search strategies:

- "Braces"[Mesh] AND "Scoliosis"[Mesh] AND
(hasabstract[text] AND (Clinical Trial[ptyp] OR
Meta-Analysis[ptyp] OR Practice Guideline[ptyp] OR
Randomized Controlled Trial[ptyp] OR Review [ptyp])) (155 papers).

- ("Scoliosis/therapy"[Mesh]) AND "Braces"[Mesh] AND compliance (78 papers)

- "Scoliosis"[Mesh] AND "Braces"[Mesh] AND ("infant, newborn"[MeSH Terms] OR "infant"[MeSH Terms:noexp] OR "child, preschool"[MeSH Terms]) (183 papers)

We selected from the titles a total of 224 papers and, looking at the abstracts, 102 were selected and retrieved in full text. We also searched: the abstracts of all SOSORT Meetings, from the first one in 2003 to 2010; the personal files and knowledge of all the authors; the papers retrieved with all the other searches listed in these Guidelines; the references sections of all retrieved papers. The selection criteria used in all these searches were: pertinence for the topic "Brace treatment"; presence of the abstract; numerical results in relation to scoliosis; retrievability in full text; all languages.

\section{Results}

SOSORT has published in Scoliosis Journal two Consensus Papers on bracing titled "SOSORT consensus paper on brace action: TLSO biomechanics of correction (investigating the rationale for force vector selection)" [130], and "Guidelines on "Standards of management of idiopathic scoliosis with corrective braces in everyday clinics and in clinical research": SOSORT Consensus 2008" [114]: they can serve as reference for specific insights.

\section{Efficacy in adolescents}

Recently a Cochrane review $[131,132]$ has been published, that found that there is very low quality evidence in favor of using braces, making generalization very difficult. This review included:

- one multicenter prospective international observational study that provided very low quality evidence in favor of the efficacy of bracing [133]: Nachemson evaluated 240 patients with thoracic or thoracolumbar curves between $25^{\circ}$ and $35^{\circ}$, aged between 10 and 15 years, of which 129 were only observed and 111 treated with thoracolumbar braces. Progression of 6 or more degrees at 2 radiographic follow-ups to the first visit was considered an index of failure of the selected treatment (observation versus brace treatment). At 4 years of follow-up, the success rate for brace treatment was $74 \%$ (range, $52-84 \%$ ), whereas the rate for observation was 34\% (range, 16-49\%).

- a randomized controlled trial that demonstrated with very low quality evidence that a plastic TLSO 
brace is more effective than an elastic brace [134]. Wong randomized forty-three subjects to SpineCor or rigid orthosis group. Although it has been stated that the authors where not trained to fit the SpineCor brace [135] the authors concluded that $68 \%$ of the subjects in the SpineCor group and 95\% of the subjects in the rigid orthosis group did not show curve progression, with a significant difference. The 2 groups had similar responses to a patient acceptance questionnaire.

The Cochrane review concluded that further research could change the actual results and our confidence in them; in the meantime, patients' choices should be informed by multidisciplinary discussion. Future research should focus on short- and long-term patientcentered outcomes, in addition to measures such as Cobb angles. RCTs and prospective cohort studies should follow both the Scoliosis Research Society and Society on Scoliosis Orthopedic and Rehabilitation Treatment criteria for bracing studies.

In fact, beyond the previously reported papers, the SRS defined some methodological criteria to be followed during brace cohort studies [136]. The optimal inclusion criteria consist of: age 10 years or older when brace is prescribed, Risser 0-2, primary curve angles 25 degrees40 degrees, no prior treatment, and, if female, either premenarchal or less than 1 year postmenarchal. Assessment of brace effectiveness should include: (1) the percentage of patients who have $<$ or $=5$ degrees curve progression and the percentage of patients who have $>$ or $=6$ degrees progression at maturity, (2) the percentage of patients with curves exceeding 45 degrees at maturity and the percentage who have had surgery recommended/undertaken, and (3) 2-year follow-up beyond maturity to determine the percentage of patients who subsequently undergo surgery. All patients, regardless of subjective reports on compliance, should be included in the results (intent to treat). Every study should provide results stratified by curve type and size grouping. Cohort studies respecting the SRS criteria can be considered of high methodological quality. Until now 6 papers have been published with these characteristics [76,78,137-139].

Together with these criteria, SOSORT offered the "Standards of management of idiopathic scoliosis with corrective braces in everyday clinics and in clinical research" [114], that include 14 recommendations, grouped in 6 Domains (Experience/competence, Behaviours, Prescription, Construction, Brace Check, Followup). Cohort studies using the SOSORT criteria can be considered of high quality in terms of patient and treatment management. Until now 2 papers have been published with these characteristics $[76,78]$.
Looking at the papers published using the SRS and/or SOSORT criteria we found:

- Janicki et al [138], following the SRS criteria, retrospectively compared in an "intent-to-treat" analysis the effectiveness of the custom thoracolumbosacral (TLSO) worn 22 hours/day and the Providence orthosis worn 8-10 hours/night. There were 48 patients in the TLSO group and 35 in the Providence group. In the TLSO group, only 7 patients (15\%) did not progress (< or $=5$ degrees), whereas 41 patients (85\%) progressed by 6 degrees or more, including the 30 patients whose curves exceeded 45 degrees. Thirty-eight patients (79\%) required surgery. In the Providence group, 11 patients (31\%) did not progress, whereas 24 patients (69\%) progressed by 6 degrees or more, including 15 patients whose curves exceeded 45 degrees. Twenty-one patients (60\%) required surgery.

- Coillard et al [137], following the SRS criteria, studied prospectively a cohort of 254 patients treated with the Dynamic SpineCor brace. Successful treatment (correction $>5^{\circ}$ or stabilization $\pm 5^{\circ}$ ) was achieved in 165 patients of the 254 patients (64.9\%). 46 immature patients (18.1\%) required surgical fusion whilst receiving treatment. Two patients out of $254(0.7 \%)$ had curves exceeding $45^{\circ}$ at maturity.

- Negrini et al [78], following both the SRS and SOSORT criteria, retrospectively studied a cohort of 42 females and four males treated according to individual needs, with Risser casts, Lyon or SPoRT braces (14 for 23 hours per day, 23 for $21 \mathrm{~h} / \mathrm{d}$, and seven for $18 \mathrm{~h} / \mathrm{d}$ at start). No patient progressed beyond 45 degrees, nor was any patient fused, and this remained true at the two-year follow-up for the $85 \%$ that reached it. Only two patients (4\%) worsened, both with single thoracic curve, 25-30 degrees Cobb and Risser 0 at the start.

- Aulisa et al [76], following both the SRS and SOSORT criteria, retrospectively reviewed a cohort of fifty adolescent females with thoraco-lumbar curves treated with the Progressive Action Short Brace (PASB). Curve correction was accomplished in $94 \%$ of patients, whereas a curve stabilisation was obtained in $6 \%$ of patients. No patient required surgery, nor anyone progressed beyond $45^{\circ}$.

- Gammon et al [139], following the SRS criteria, compared treatment outcomes of 2 cohorts of patients treated via either a conventional rigid thoracolumbosacral orthoses (TLSO: 35 patients) or a SpineCor nonrigid orthosis (32 patients). No significant difference was found using the more strict outcome measure (< or $=5$-degree curve progression) as the success rates were $60 \%$ for TLSO and $53 \%$ for 
SpineCor. Looking at patients who reached 45 degrees, the success rates were $80 \%$ for TLSO and $72 \%$ for SpineCor with no significant difference.

- Finally, Zaborowska-Sapeta et al [140], including the patients according to the SRS criteria, prospectively followed 79 patients treated with Cheneau brace. At one year after weaning the brace they found improvement in $25.3 \%$, stabilization in $22.8 \%$, progression of the Cobb angle up to below $50^{\circ}$ in $39.2 \%$ and progression beyond $50^{\circ}$ in $12.7 \%$, the latter was considered surgical indication.

In summation, these papers show that: high variability among results of bracing is confirmed [76,78,137-140], and this is incredibly high mainly with rigid bracing [76,78,138-140]; even if soft braces [137,139] can have results better than [138], or at least comparable to [139], some types of rigid braces, the best results have been achieved with the last, when using SOSORT criteria $[76,78,140]$. It must also be noted that high variability can be found between different publications in the type of scoliosis treated, and thus a different outcome in treatment. A geographical distribution of different types of scoliosis should be taken in consideration and all results should be presented accordingly.

When it comes to previously published results, Dolan [141] performed a systematic review of the English literature: only studies written in English were included, if observation or a TLSO was evaluated and if the sample closely matched the current indications for bracing (skeletal immaturity, age 15 years or less, Cobb angle between $20^{\circ}$ and $45^{\circ}$ ). Eighteen studies were included (3 observation only, 15 bracing). Despite some uniformity in surgical indications, the surgical rates were extremely variable, ranging from $1 \%$ to $43 \%$ after bracing, and from $13 \%$ to $28 \%$ after observation. When pooled, the bracing surgical rate was $23 \%$ compared with $22 \%$ in the observation group. It was concluded that, based on the evidence presented, one cannot recommend one approach over the other to prevent the need for surgery in AIS: the use of bracing relative to observation is supported by "troublingly inconsistent or inconclusive studies of any level".

Unfortunately, the inclusion criteria used by Dolan resulted in the exclusion of some retrospective papers already published at that time, since they had used exercises together with bracing [142-144]:

- Weiss [144] considered three hundred and fortythree scoliosis patients (females only) of various etiology, with a curvature of 33.4 degrees. Forty-one patients (11.95\%) had had surgery. In patients with adolescent idiopathic scoliosis, the incidence of surgery was $7.3 \%$.
- Rigo [142] considered 106 patients with curves on average of $30^{\circ}$ at start, out of which 97 were followed up, and six cases (5.6\%) ultimately underwent spinal fusion. A worst case analysis, which assumes that all nine cases that were lost to follow-up had operations, brings the uppermost number of cases that could have undergone spinal fusion to 15 (14.1\%).

- Maruyama [143] reviewed 328 females with an average 32.4 degree Cobb angle. Surgery was recommended when curvature progressed to > 50 degrees. Twenty (6.1\%) were treated with spinal fusion. The remaining showed no significant increase in magnitude of curvature.

In 2008 also Negrini [91] reported on surgery rates in curves over $30^{\circ}$ at first evaluation, treated with brace and exercises: they were a subgroup of 28 out of 112 patientsof 23.4 Cobb degrees at the start of treatment. The rate of surgery was $1.9 \%$ (efficacy analysis), and 9.1\% (worst case) versus $0.9 \%$ and $4.5 \%$ respectively in the whole group observed. All these studies, if included in the Dolan meta-analysis, would have changed the overall results in favor of bracing.

Some years ago, Rowe [145] conducted a meta-analysis to compare the consistency of outcomes among several of the oldest studies. Of a total of 1910 patients, 1459 received brace treatment, 322 electrostimulation, and 129 only observation. The weighted mean success rate was 0.39 for electrostimulation, 0.49 for observation, 0.60 for braces worn $8 \mathrm{hr}$ daily, 0.62 for braces worn $16 \mathrm{hr}$ daily, and 0.93 for braces worn $23 \mathrm{hr}$ daily, the last of which was the statistically most efficacious treatment method. The most efficacious brace system was the Milwaukee brace vs. others, while the Charleston brace, which was worn only nighttimes, was the least successful, but yet statistically still better than observation alone.

Are there braces that are better than others? In the literature there are very few studies comparing different braces. SOSORT experts, when facing the issue of trying to find a Consensus on the way to achieve the best possible correction through bracing, were not able to reach it [130]: while the importance of the three point system mechanism was stressed, options about proper pad placement on the thoracic convexity were divided $50 \%$ for the pad reaching or involving the apical vertebra and $50 \%$ for the pad acting caudal to the apical vertebra. There was agreement about the direction of the vector force, $85 \%$ selecting a 'dorso lateral to ventro medial' direction, but not about the shape of the pad to produce such a force. Principles related to three-dimensional correction achieved high consensus (80\%-85\%), but suggested methods of correction were quite diverse. This 
situation is reflected in the different corrective systems used throughout the world.

Looking at studies comparing different braces, we have already reported some studies:

- an RCT [134], that found a TLSO more effective than SpineCor;

- one meta-analysis [145], that was in favor of the Milwaukee brace, with Charleston being the less efficacious;

- one systematic review [141], that found the following pooled surgery rates: Boston Brace 12-17\%; various braces (Boston-Charleston-TLSOs) 27-41; nigh time braces (Providence or Charleston braces) 1725\%; TLSO or Rosenberg brace 25-33; Wilmington 19-30\%;

- two retrospective studies: one [138] obtained the best results with the Providence night time orthosis over a TLSO, the other [139] reported equal results with a rigid TLSO and SpineCor;

Reviewing the literature we also found:

- Among the oldest studies, Bunnell [146] reported similar results with a TLSO and Milwaukee brace in a preliminary retrospective study, while Montgomery [147] found that the Boston Brace was more successful than the Milwaukee brace irrespective of initial curve magnitude and skeletal maturity

- Katz [148] compared the Boston Brace to the Charleston bending brace. The first was more effective than the second, both in preventing curve progression and in avoiding the need for surgery. These findings were most notable for patients with curves of $36^{\circ}$ to $45^{\circ}$, in whom $83 \%$ of those treated with a Charleston brace had curve progression of more than 5 degrees, compared with $43 \%$ of those treated with the Boston Brace.

- Howard [149] presented a retrospective cohort study on 170 patients who completed brace treatment: Forty-five patients with TLSO showed a mean progression of the curve of 1.1 degrees, 95 with Charleston worsened 6.5 degrees, and 35 with Milwaukee 6.3 degrees. Proportion of patients with more than 10 degrees of curve progression was $14 \%$ with TLSO, 28\% with Charleston, and 43\% with Milwaukee brace while those who underwent surgery were $18 \%, 31 \%$, and $23 \%$ respectively.

- Weiss [79] performed a comparison of the survival rates of the Cheneau versus SpineCor with respect to curve progression and duration of treatment during pubertal growth spurt in two cohorts of patients followed up prospectively. At 24 months of treatment, $73 \%$ of the patients with a Cheneau brace and
$33 \%$ of the patients with the SpineCor where still under treatment with their original brace; at 42 months the same percentages were $80 \%$ and $8 \%$ respectively.

- Yrjonen [150] studied retrospectively the Providence nighttime used by 36 lumbar and thoracolumbar scoliosis consecutive female patients with less than 35 degrees: progression of the curve $>5$ degrees occurred in 27\%, versus 36 matched patients treated with the Boston full-time that progression in $22 \%$ of cases.

- Negrini [151] compared the classical Lyon brace to the newly developed Sforzesco brace, based on the SPoRT concept (Symmetric, Patient-oriented, Rigid, Three-dimensional, active) with prospective, matched pairs controlled study. All radiographic and clinical parameters decreased significantly with treatment in both groups, apart from thoracic Cobb degrees with the Lyon brace. The Sforzesco brace had better results than the Lyon brace radiographically, for sagittal profile, aesthetics, and patient recovery (12 improved and 3 unchanged vs 8 and 5). - Negrini [112] also studied a prospective cohort who had refused surgery treated with the Sforzesco brace to a Risser cast retrospective control group. Results were comparable between the two groups, with only minor differences in terms of scoliosis correction. On the contrary, straightening of the spine (decrease of the sagittal physiological curves) was much higher with the cast, while it was not clinically significant with the brace.

All these studies are not directly comparable, and the learning curve of the different systems can sometimes play a role in explaining the results. Moreover, in comparative studies the specific competence in making a specific brace can play a major role [135]: in this respect, even if it is not considered a good standard, comparison with historical controls treated with braces used before by the same treating team can offer good insights $[112,138,139,150,151]$. Today it is not possible to state with any certainty which brace is better than the other, and this is one of the reasons that drove the official publication of SOSORT to develop the Brace Thematic Series [152], where the different concepts are presented to allow a good comparison and a greater understanding of these treatment instruments [153-155]. Nevertheless it is already possible to see some trends:

- new alternative concepts have been developed trying to substitute the most invasive braces: this was true some years ago for TLSOs instead of Milwaukee, more recently for night time bending braces or SpineCor instead of TLSOs, and in the last years for 
the Sforzesco brace instead of casting; not all these new concepts have been able to prove their efficacy. - in the meantime there is a struggle (mainly inside SOSORT) to progressively refine and strengthen some old concepts, like the Cheneau, Boston or Lyon braces, but also newly developed ones, like the Sforzesco and SpineCor.

In summation, examining all these studies in adolescent patients, it is clearly evident that something beyond the instrument (brace) plays a role in final results. These factors can include dosage, quality of bracing, compliance to treatment [156-158], family history, type of scoliosis and even a geographical distribution, but also team approach [114], that we will briefly review below.

Dosage, compliance and quality of bracing Looking for dosage effect, Dolan did not find differences among the groups $16-18$ hours (19-34\% surgery rate), 18-23 hours (21-26\%) and night time (17-25\%) [141]; on the contrary, the meta-analysis by Rowe [145] reported that the twenty-three-hour regimens were significantly more successful than any other treatment, while the difference between the eight and sixteen-hour regimens was not significant. More recently, while Allington [159] reported no differences between full-time and part-time brace prescription both in curves below $30^{\circ}$ and between $30^{\circ}$ and $40^{\circ}$, Katz [160] has been able to check the real use of the brace by the patient through an heat sensor. A logistic regression analyses showed a "dose-response" curve in which the greater number of hours of brace wear correlated with lack of curve progression. Curves did not progress in $82 \%$ of patients who wore the brace more than twelve hours per day, compared with only $31 \%$ of those who wore the brace fewer than seven hours per day. As a result, dosage can be considered a possible major factor in explaining some of the results of bracing: in fact it has been shown that the more hours of daily brace weaning, the more the deformity comes back from the maximal correction ("concertina effect") [161].

Adherence to treatment is the second main issue to be considered. Many studies have underlined that referred compliance is correlated with final results $[156,157,162]$; compliance to bracing has been correlated to Quality of Life and psychological issues [163-166], even if patients declare that they would adhere to treatment provided its efficacy is proven [167]. Since patients during clinical evaluations overstate their adherence to treatment [168], heat sensors have been developed to check real compliance: it has been confirmed that both reported and estimated hours of brace wearing are inaccurate [169-174], and found that compliance is not correlated with the hours of bracing prescribed [173]. Night time wear is more accepted than daytime [175] and a "doseresponse" to bracing seems to be confirmed $[160,176]$. It has also been proposed that it is possible to develop a progression model in single patients with a formula including the risk of progression at the beginning of brace treatment, plus the use in terms of brace tightness and wear time [177]. Nevertheless, compliance issues should be regarded from a wider angle than what usually reported, i.e. that, since patients are not compliant, bracing is not effective. SOSORT propose that compliance should be considered in terms of management of patients: in this perspective adherence to treatment is a characteristic neither of the treatment only, nor of the patient alone, but of the good interaction between these two factors, based on the active approach by an expert treatment team able to reduce the burden of the brace and increase the coping abilities of the patient [114,178]. Mainly for these reasons, SOSORT proposed its Recommendations [114].

Finally, the important factor quality of bracing. There is quite an agreement to judge it according to the inbrace correction [156-158,179-184], even if percentages reported in the literature as prognostic factors of final good results are quite variable from a minimum of 20 $25 \%$ to $40-50 \%$ [156,157,185]. In-brace correction has become on one side the starting point to develop new braces $[67,68,113,186-190]$, on the other a biomechanical reference for various studies [183,191,192]: recently a finite element model study confirmed the importance of immediate in-brace correction to predict long-term outcome of bracing treatment [183]. Other factors such as the absolute reduction of the Cobb angle (i.e., in rigid curves over 50 degrees) or $3 \mathrm{D}$ correction might also be important and should be considered in the future [180]: in fact, it is still possible that a great in-brace reduction corresponds to a worsening of other parameters, e.g. in the sagittal plane, finally driving to a flat-back and worse functional results [112]. In this respect, it is mandatory not to confuse the in-brace correction with the success of an orthotic treatment: while in-brace correction studies should be considered preliminary, only results at the end of treatment and/or at minimum of 12 years post treatment follow-up should be regarded as proves of efficacy. In any case, according to the actual knowledge in-brace correction should be regarded as the way to individually judge the quality of the brace applied to single patients.

All the criteria for inclusion, exclusion and outcome hava some drawbacks; one main problem is the fact that even the noncompliant patients are to be included in the studies and it seems that this is one of the criteria that is most frequently "forgotten". In this situation it is extremely difficult to compare two different studies and often the professional trying to offer the best treatment 
for his patients has the difficult task of comparing "apples with oranges". Apart from the inclusion and exclusion criteria as well as the assessment of brace effectiveness proposed by the SRS Committee, a few more guidelines for future studies should be proposed. All patients that accepted the treatment in a given time period should be included in the study regardless of their compliance. Patients that withdrawn from the treatment (changed the type of treatment, had surgery recommendation, etc.), regardless of their outcome, should be considered as failure of that specific treatment. All the patients that accepted a specific treatment should be followed up for at least 1-2 years after the completion of treatment and measurements should be taken at the beginning of the treatment, at the weaning point and at follow-up.

Efficacy in other populations Adolescent idiopathic scoliosis with curves below $40-45^{\circ}$ and still growing is the main field of brace treatment [141], but it has been applied as well in other populations, that we will briefly review here.

In juvenile idiopathic scoliosis, historically the percentages of surgery after treatment with braces ranged widely, with Tolo [193] reporting 27.2\%, Figueiredo [194] 62\%, Mannherz [195] 80\%, McMaster [196] 86\% and Kahanovitz [197] 100\%. This clearly correlates with the difficulty in this specific population, where the expected progression rate could range between 70 and 95\% [102]. More recently Coillard [102] reported that, with the SpineCor brace, out of 67 patients with a definite outcome, $32.9 \%$ corrected their Cobb angle by at least $5^{\circ}$ and $10.5 \%$ had a stabilization of their Cobb angle, while $37.3 \%$ of patients where recommended for surgery before the authorized end of treatment (before skeletal maturity). Results depended on the amplitude of the Cobb angle: $26.3 \%$ of the patients with curves under 25 degrees eventually needed surgery while $51.8 \%$ of the second group $\left(>25^{\circ}\right)$ had surgery recommended. Finally, Fusco [198] found a percentage of $9 \%$ of juvenile patients treated conservatively who finished treatment over $45^{\circ}$.

Also in infantile idiopathic scoliosis reported results are quite variable, as well as the treatment applied: serial casting is the most advocated [111,199-202], but also bracing alone has been used [199-201,203], mainly the Milwaukee brace [201,203]. The few case series reported generally include few patients with variable results, from a $100 \%$ surgery rate [204], to around 50\% [199] or much less [201,205] (mainly if casts are used [199]). Mehta reported the widest case series of 136 children followed up for nine years: 94 children, referred and treated in the early stages (mean age 19 months- 6 to 48 , Cobb angle $32^{\circ}-11^{\circ}$ to $65^{\circ}$ ), resolved the deformity by a mean age of three years and six months, with no need of further treatment; 42 children, referred late (mean age 30 months- 11 to 48 , Cobb angle $52^{\circ}-23^{\circ}$ to $92^{\circ}$ ), reduced but not reversed scoliosis; 15 children $(35.7 \%)$ were fused. The hypothesis of the author is that scoliosis can be reversed by harnessing the vigorous growth of the infant to early treatment by serial corrective plaster jackets [111].

Like in the adolescent type, puberty is the worst period also for infantile scoliosis, when surgery is mostly required [201]; single thoracic curves seem to have the worst outcomes when compared to double structural ones [203]; it has also been reported that best results are obtained in progressive types if treatment is started when the angulation is still under 30 degrees [205], or $60^{\circ}$ and younger age [202], again mainly with casting $[199,202]$. When scoliosis is resolved or stabilized nonoperatively at an acceptable Cobb angle also normal cosmesis and pulmonary function is obtained; apparently this is not true if surgery is performed [200].

Finally, two papers recently focused on other groups:

- scoliosis over $45^{\circ}$ who refused to be operated [77]. Out of 28 patients (curve range $45-58^{\circ} \mathrm{Cobb}$ ) who reached the end of treatment (brace and exercises for 4.5 years) two patients (7\%) remained above $50^{\circ}$ but six patients $(21 \%)$ finished between $30^{\circ}$ and $35^{\circ}$ and 12 patients (43\%) finished between $36^{\circ}$ and $40^{\circ}$ Cobb. Improvements have been found in $71 \%$ of patients and a $5^{\circ} \mathrm{Cobb}$ progression in one patient.

- scoliosis of Risser 4-5 up to 20 years of age [206] (residual growth was $0.9 \mathrm{~cm}$ ). Out of 23 patients requiring treatment or for esthetic reasons, or to try to reduce the deformity, curve improvements were found in $48 \%$ and decrease of the Esthetic Index in $30 \%$.

Team role in bracing SOSORT already produced a set of Recommendations in the paper "Standards of management of idiopathic scoliosis with corrective braces in everyday clinics and in clinical research" [114], grouped in 6 Domains: Experience/competence, Behaviours, Prescription, Construction, Brace Check, Follow-up. These recommendations, integrally reported below, constitute part of these Guidelines.

Recommendation 1 (Experience-competence)

The MD responsible for the treatment has to be experienced and should fulfill all these requirements:

1. training by a previous master (i.e. MD with at least 5 years of experience in bracing) for at least 2 years

2. at least 2 years of continuous practice in scoliosis bracing

3. prescription of at least 1 brace per working week ( 45 per year) over the last 2 years

4. evaluation of at least 4 scoliosis patients per working week ( 150 per year) over the last 2 years 
Due to the actual situation of conservative treatment in many countries, this must be considered the ideal to be reached as soon as possible through education. Nevertheless, it must be recognized that experience and preparation is the only way to avoid problems to patients and reach adequate results in this field.

Recommendation 2 (Experience-competence)

The CPO constructing braces has to be experienced and should fulfill all these requirements

1. working continuously with a master MD (i.e. a MD fulfilling to recommendation 1 criteria) for at least 2 years

2. at least 2 years of continuous practice in scoliosis bracing

3. construction of at least 2 braces per working week $(\sim 100$ per year) in the last 2 years

Due to the actual situation of conservative treatment in many countries, this must be considered the ideal to be reached as soon as possible through education. Nevertheless, it must be recognized that experience and preparation is the only way to avoid problems to patients and reach adequate results in this field.

Recommendation 3 (Behaviors)

To ensure optimum results, the MD, CPO and physiotherapist (PT) must work together as an interprofessional team. This can be accomplished, even if they are not currently located in the same workplace, through continuous exchange of information, team meetings, and verification of braces in front of single patients.

Recommendation 4 (Behaviors)

Commitment, time and counseling to increase compliance: MDs, CPOs and PTs have to give thorough advice and counseling to each single patient and family each time it is needed (at each contact for MDs and CPOs) provided they give as a team the same messages previously agreed upon.

Recommendation 5 (Behaviors)

All the phases of brace construction have to be followed for each single brace

1. prescription by a well trained and experienced MD (fulfilling recommendation 1 criteria)

2. construction by a well trained and experienced CPO (fulfilling recommendation 2 criteria)

3. checked by the MD in cooperation with the CPO, and possibly the PT

4. correction by the $\mathrm{CPO}$ according to $\mathrm{MD}$ indications

5. follow-up by the CPO, MD and PT.

Recommendation 6 (Prescription)

In each single prescription of a brace (case by case), the MD must:

1. write the details of brace construction (where to push and where to leave space, how to act on the trunk to obtain results on the spine) when not already defined "a priori" with the CPO
2. prescribe the exact number of hours of brace wearing

3 . be totally convinced of the brace proposed and committed to the treatment

4. use any ethical means to increase patient compliance, including thorough explanation of the treatment, aids such as photos, brochures, video, etc.

Recommendation 7 (Construction)

In each single construction of a brace, case by case, the CPO has to:

1. check the prescription and its details and eventually discuss them with the prescribing $\mathrm{MD}$, if needed, before construction

2. fully execute the agreed prescription

3 . be totally convinced of the brace proposed and committed to the treatment

4. use any ethical means to increase patient compliance, including thorough explanation of the treatment, aids such as photos, brochures, video, etc.

Recommendation 8 (Brace Check)

In each single check of a brace, case by case, the responsible MD in partnership with the CPO has to:

1. verify accurately if it fits properly and fulfils the needs of the individual patient

2 . check the scoliosis correction in all three planes (frontal, sagittal and horizontal)

3. check clinically the esthetic correction

4. maximize brace tolerability (reduce visibility and allow movements and activity of daily life as much as possible for the chosen technique)

5. apply all changes needed and, if necessary, even rebuild the brace without extra-charge for patients

6. check the corrections applied

7. check that the patient (and/or his/her parents) is able to apply or put on the brace properly

8. access the patient's mood and counsel with the family at brace delivery and at other follow-ups.

Recommendation 9 (Brace Check)

The check of each single brace must be a clinical and/or radiographic check.

Recommendation 10 (Follow-up)

The MD, CPO and PT must check the brace and patient compliance regularly (MDs and CPOs each time they see the patient), and reinforce the usefulness of brace treatment to the patient and his/her family.

Recommendation 11 (Follow-up)

The MD has to follow-up the braced patient regularly, at least every 3 to 6 months. Standard intervals have to be reduced according to individual needs (first brace, growth spurt, progressive or atypical curve, poor compliance, request of other team members-CPO, PT ...). Using tools (written protocols, recalls, etc.) to keep patients informed of their follow-up is strongly suggested. 
Recommendation 12 (Follow-up)

The brace has to be changed for a new one as soon as the child grows or the brace loses efficacy, and this need can be suggested by the $\mathrm{CPO}$, but is the responsibility of the treating MD.

Recommendation 13 (Follow-up)

The CPO has to regularly check the brace. To avoid any problems, he/she has to refer to the treating MD.

Recommendation 14 (Follow-up)

The PT has to check the brace regularly. To avoid any problems, she/he has to refer to the treating MD. As a member of the treating team, he/she has to be trained to face the problems of compliance, or the needs for more explanation by the patient or his/her family. In case she/he is not entirely a member of the treating team the PT must not act autonomously and must refer to the treating MD.

Other issues It is not possible in this review of the literature to fully consider the complex and currently debated topics like:

- CAD-CAM versus plaster molding in brace construction: research is reaching the conclusion that the way in which the brace is constructed does not interfere with final results, nor with patients' sensations [180,187,189,207];

- finite element modeling of brace efficacy: models are showing the efficacy of bracing in reducing spinal load and applying corrective moments to the spine; moreover they are helping in refining brace construction, but there is still a long way to go [183,192,208-210];

- 3D classifications and their effect on brace construction and results' evaluation: some more years are needed to reach the first clinically useful applications $[65,69-72,211]$.

These topics, and others that research will produce in the next years, will be reviewed and considered in depth in next Editions of the SOSORT Guidelines.

\section{Recommendations on "Bracing"}

1. Bracing is recommended to treat adolescent idiopathic scoliosis (SoR: B) (SoE: III) [76,78,131,132,137-139]

2. Bracing is recommended to treat juvenile and infantile idiopathic scoliosis as the first step in an attempt to avoid or at least postpone surgery to a more adequate age (SoR: B) (SoE: IV) [102,193,194,198-201,203]

3. Casting is recommended to treat infantile idiopathic scoliosis to try stabilizing the curve (SoR: B) (SoE: IV) [111,199-202]

4. It is recommended not to apply bracing to treat patients with curves below $15 \pm 5^{\circ} \mathrm{Cobb}$, unless otherwise justified in the opinion of a clinician specialized in conservative treatment of spinal deformities (SoR: B) (SoE: VI)

5. Bracing is recommended to treat patients with curves above $20 \pm 5^{\circ} \mathrm{Cobb}$, still growing, and demonstrated progression of deformity or elevated risk of worsening, unless otherwise justified in the opinion of a clinician specialized in conservative treatment of spinal $\begin{array}{llll}\text { deformities } & \text { (SoR: } & \text { B) } & \text { (SoE: }\end{array}$ [76,78,131,132,137-139,141]

6. It is recommended that each treating team provide the brace that they know best and are most prepared to manage: due to the actual knowledge, there is no brace that can be recommended over the others (SoR: C) (SoE: IV) [134,138,139,141,145]

7. It is recommended that braces are worn full time or no less than 18 hours per day at the beginning of treatment, unless otherwise justified in the opinion of a clinician specialized in conservative treatment of spinal deformities (SoR: B) (SoE: IV) [145,160]

8. Since there is a "dose-response" to treatment, it is recommended that the hours of bracing per day are in proportion with the severity of deformity, the age of the patient, the stage, aim and overall results of treatment, and the achievable compliance (SoR: B) (SoE: IV) $[145,160]$

9. It is recommended that braces are worn until the end of vertebral bone growth and then the wearing time is gradually reduced, unless otherwise justified in the opinion of a clinician specialized in conservative treatment of spinal deformities (SoR: B) (SoE: V)

10. It is recommended that the wearing time of the brace is gradually reduced, while performing stabilizing exercises, to allow adaptation of the postural system and maintain results (SoR: B) (SoE: IV) [91,142-144,212]

11. It is recommended that any mean is used to increase and monitor compliance, including heat sensors and a careful adherence to the recommendations defined in the SOSORT Guidelines for Bracing Management (SoR: B) (SoE: VI) [114,169-174]

12. It is recommended that quality of the brace is checked through an in-brace x-ray (SoR: B) (SoE: IV) [156-158,179-184]

13. It is recommended that the prescribing physician and the constructing orthotist are experts according to the criteria defined in the SOSORT Guidelines for Bracing Management (SoR: B) (SoE: V) [114]

14. It is recommended that bracing is applied by a well trained therapeutic team, including a physician, an orthotist and a therapist, according to the criteria defined in the SOSORT Guidelines for Bracing Management (SoR: B) (SoE: V) [114]

15. It is recommended that all the phases of brace construction (prescription, construction, check, correction, follow-up) are carefully followed for each single 
brace according to the criteria defined in the SOSORT Guidelines for Bracing Management (SoR: A) (SoE: V) [114]

16. It is recommended that the brace is specifically designed for the type of the curve to be treated (SoR: A) (SoE: V)

17. It is recommended that the brace proposed for treating a scoliotic deformity on the frontal and horizontal planes should take into account the sagittal plane as much as possible (SoR: A) (SoE: V)

18. It is recommended to use the least invasive brace in relation to the clinical situation, provided the same effectiveness, to reduce the psychological impact and to ensure better patient compliance (SoR: B) (SoE: V)

19. It is recommended that braces do not so restrict thorax excursion in a way that reduces respiratory function (SoR: A) (SoE: V)

20. It is recommended that braces are prescribed, constructed and fitted in an out-patient setting (SoR: B) (SoE: VI)

\section{Conservative treatments other than bracing Physiotherapeutic Specific Exercises to prevent scoliosis progression during growth Methods}

In February 2011 we performed a search of Medline from its inception, with no language limitations. We used the terms ("Exercise Therapy"[Mesh]) AND "Scoliosis"[Mesh] and we found 206 papers; after reviewing the titles, 66 were considered of interest; looking at the abstracts 41 were selected and retrieved in full text. We also searched: the abstracts of all SOSORT Meetings, from the first one in 2003 to 2010; the personal files and knowledge of all the authors; the papers retrieved with all the other searches listed in these Guidelines; the references sections of all retrieved papers. The selection criteria used in all these searches were: pertinence for the topic "Physiotherapeutic Specific Exercises to prevent scoliosis progression"; presence of the abstract; numerical results in relation to scoliosis; retrievability in full text; all languages.

\section{Results}

SOSORT has published in Scoliosis Journal a Consensus Paper titled "Physical Exercises in the Treatment of Idiopathic Scoliosis at Risk of brace treatment-SOSORT Consensus paper 2005" [213]: this can serve as reference for specific insights. In this Consensus some characteristics of Physiotherapeutic Specific Exercises have clearly been stated with almost unanimity among SOSORT experts: auto-correction in $3 \mathrm{D}$, training in ADL, stabilizing the corrected posture, and patient education should be always included.

Moreover, a Cochrane review on exercises that follows the protocol presented in 2009 [214], has been submitted and it is now under review: this review found 2 papers of high interest, one RCT that provided low quality evidence in favor of exercises used together with other treatments [215], and one cohort observational prospective trial with a concurrent control group that gave very low quality evidence in favor of specific versus general exercises to avoid brace prescription [216].

In the orthopaedic literature prevails the so-called "exercise dogma" $[217,218]$, that states that exercises are not useful for scoliosis treatment; this is widespread $[48,219,220]$, and presumably comes from an old paper published down in 1979 [221], the only one against the effectiveness of Physiotherapeutic Specific Exercises. Consequently, the old systematic reviews concluded on the inefficacy of exercises [222]; more recently, three comprehensive systematic reviews published in last years by the same group [223-225], and to a lesser extension another one [226,227], have exhaustively evaluated studies on the efficacy of specific exercise programs in reducing the probability of progression of idiopathic scoliosis. These reviews found that the general methodology used in studies published so far has generally been of poor quality, even though, except for 1 study (the oldest one) [221], all study results indicate that treatment is useful [215,216,228-244]. The authors of these systematic reviews concluded that, as far as we know today, Physiotherapeutic Specific Exercises may be proposed to patients.

The exercises papers have been tentatively classified according to the auto-correction proposed [225]: extrinsic (maximal correction obtained also with the help of gravity, positioning devices and/or limbs placement) [228,235-239,242-244], intrinsic (maximal correction achievable without any external aids) $[216,229,230,232,234]$, no auto-correction but asymmetric exercises $[215,240,241]$, no auto-correction and symmetric exercises [221,231,233]. According to these reviews, until now the Physiotherapeutic Specific Exercises School with some published proves of efficacy (in alphabetical order) include: DoboMed [235], Lyon $[229,230,234]$, MedX [240,241], Schroth (either as Scoliosis Intensive Rehabilitation [228,237,242,245], or outpatient approach $[238,244])$, SEAS [216,232], side shift [236,239,243].

A major drawback, however, is the unevenness of information about the natural history of progression of scoliosis $[129,246]$. The probability that the curve will worsen depends on patient age at diagnosis, type and severity of curve, sex and skeletal maturity $[129,247,248]$. From $25 \%$ to $75 \%$ of curves found at screening may remain unchanged, whereas from $3 \%$ to $12 \%$ of curves may improve $[35,129]$. Treatment decisions should be individualized, considering the probability of curve progression, based on curve magnitude, 
skeletal maturity, patient age and sexual maturity $[48,249]$.

Finally, we have to consider also the concept of acceptability of treatment together with efficacy and effectiveness: when facing a progression risk of $25 \%$, families preferred the use of Physiotherapeutic Specific Exercises for prevention instead of awaiting a possible progression of the deformity to be later treated with a brace [250].

\section{Recommendations on "Physiotherapeutic Specific Exercises} to prevent scoliosis progression during growth"

21. Physiotherapeutic Specific Exercises are recommended as the first step to treat idiopathic scoliosis to prevent/limit progression of the deformity and bracing (SoR: B) (SoE: II) [214,215,223-225]

22. It is recommended that Physiotherapeutic Specific Exercises follow SOSORT Consensus and are based on auto-correction in $3 \mathrm{D}$, training in $\mathrm{ADL}$, stabilizing the corrected posture, and patient education (SoR: B) (SoE: VI) [213]

23. It is recommended that Physiotherapeutic Specific Exercises follow one of the School that have shown the effectiveness of their approach with scientific studies (SoR: B) (SoE: III) [216,228-230,232,234-244]

24. It is recommended that Physiotherapeutic Specific Exercise programs are designed by therapists specifically trained in the School they use (SoR: B) (SoE: VI)

25. It is recommended that Physiotherapeutic Specific Exercises are proposed by therapists included in scoliosis treatment teams, with close cooperation between all members (SoR: B) (SoE: V) [114]

26. It is recommended that Physiotherapeutic Specific Exercises are individualized according to patients needs, curve pattern, and treatment phase (SoR: B) (SoE: III) [216,228-230,232,234-244]

27. It is recommended that Physiotherapeutic Specific Exercises are always individualized even if performed in small groups (SoR: B) (SoE: VI)

28. It is recommended that Physiotherapeutic Specific Exercises are performed regularly throughout treatment to achieve best results (SoR: B) (SoE: VI)

\section{Physiotherapeutic Specific Exercises during brace treatment and surgical therapy Methods}

In February 2011 we performed a search of Medline from its inception, with no language limitations. For this section we used the terms ("Exercise Therapy"[Mesh]) AND "Scoliosis"[Mesh] and "Braces"[Mesh] AND "Scoliosis"[Mesh] AND (hasabstract[text] AND (Clinical Trial [ptyp] OR Meta-Analysis[ptyp] OR Practice Guideline [ptyp] OR Randomized Controlled Trial[ptyp] OR Review [ptyp])) outlined above; we also add a specific search with the terms (("Scoliosis/surgery"[Mesh]) AND
"Scoliosis/rehabilitation"[Mesh]) OR (("Scoliosis/surgery"[Mesh]) AND "Exercise Therapy"[Mesh]). We also searched: the abstracts of all SOSORT Meetings, from the first one in 2003 to 2010; the personal files and knowledge of all the authors; the papers retrieved with all the other searches listed in these Guidelines; the references sections of all retrieved papers. We finally retrieved 40 relevant papers. The selection criteria used in all these searches were: pertinence for the topic "Physiotherapeutic Specific Exercises during brace treatment and surgical therapy"; presence of the abstract; numerical results in relation to scoliosis; retrievability in full text; all languages.

\section{Results}

Even if in the past Physiotherapeutic Specific Exercises to be performed as a companion of brace treatment have been proposed by most of the authors who developed specific braces, such as for the Milwaukee [251-253], Boston [254], Lyon [255,256] and Chêneau braces [257-259], this part of conservative scoliosis treatment seems to have been neglected as well [260]. Nevertheless, recently Physiotherapeutic Specific Exercises, beyond the original ones, have been associated to classical braces, like side-shift for the Milwaukee brace $[143,261,262]$, or Schroth for the Chêneau [144,179,263-265]; moreover, the newly developed Sforzesco brace is born strictly associated with exercise performance $[77,91,266]$.

When compared to a systematic review of cohort studies on bracing that formally excluded all protocols with exercises [141], all studies combining the two treatments showed very good results [114]: surgery rate dropped from the average of $22 \%$ (observed) or $23 \%$ (treated) [141] to 0$7 \%$ in the efficacy analysis $[78,91,142-144,267]$, or $10-14 \%$ in the worst case analysis [91,142]. This was true independently by the brace used: Milwaukee and side-shift [143], Chêneau and Schroth [142,144,268], cast or Lyon or Sibilla and SEAS $[78,91]$. The only exception to this rule is a recently published paper in which exercises have not been used, that reported a $0 \%$ surgery rate according to the SRS criteria [76]; in this study SOSORT criteria [114] have been utilized: this opens up the possibility that, beyond the specific effect of exercises, the physical therapist's approach can have a fundamental role in maintaining compliance as proposed by the SOSORT Guidelines for Brace Treatment Management [114]. Another main point in this study that may have improved the compliance is that the patients were all managed by the same physician.

Recently, one paper winning the SOSORT Award has shown the importance of exercises in reducing the loss of correction in the brace weaning phase [212]; another study demonstrated some usefulness of preparation to brace exercises [233]. In this respect, an old controlled randomized study on a small population showed that in 
adolescents wearing a brace, exercises are more effective than traction in improving curvature on lateral bending (i.e. increasing mobility, that should help brace action) [269]. Historically it has been shown that thoracic flexion exercises are immediately effective in reducing the vertebral rotation and lateral deviation in Milwaukee brace [270]; but in a prospective study, no significant differences have been found between 12 compliant and 12 noncompliant patients with primary right thoracic idiopathic scoliosis treated with trunk muscles strengthening exercises and Milwaukee brace [271].

The neurophysiological basis of an integration of bracing and exercises in a complete rehabilitation program for adolescent idiopathic scoliosis has been described [272]. Most of the Schools used the same exercises during brace treatment proposed without the orthosis, even if the Lyon [256,273] and SEAS [94,212,233] ones propose specific preparatory and in-brace exercises, different from those usually performed without the brace.

Finally, exercises and surgical treatment. They have been advocated as an important part of the rehabilitation process following fusion $[16,256,274]$, nevertheless the Scoliosis Research Society surgeons, when inquired if they prescribed physical therapy at hospital discharge, answered that it was unlikely [275]. It has been reported as painful to patients 10 or more years after scoliosis surgery a highly significant pain and pain frequency reduction through a multimodal treatment including stabilizing postural and respiratory exercises lasting several hours a day (5 1/2 to 7 hours) [276].

Recommendations on "Physiotherapeutic Specific Exercises during brace treatment and surgical therapy"

29. It is recommended that Physiotherapeutic Specific Exercises are performed during brace treatment (SoR: B) (SoE: III) [78,91,142-144,267]

30. It is recommended that, while treating with Physiotherapeutic Specific Exercises, therapists work to increase compliance of the patient to brace treatment (SoR: B) (SoE: V) [114]

31. It is recommended that spinal mobilization Physiotherapeutic Specific Exercises are used in preparation to bracing (SoR: B) (SoE: II) [233,269]

32. It is recommended that stabilization Physiotherapeutic Specific Exercises in autocorrection are used during brace weaning period (SoR: B) (SoE: IV) [212]

33. It is recommended that Physiotherapeutic Specific Exercises in painful operated patients are used to reduce pain and increase function (SoR: B) (SoE: IV) [276]

\section{Other conservative treatments Methods}

In February 2011 we performed a search of Medline from its inception, with no language limitations. We used the terms (()("Musculoskeletal
Manipulations"[Mesh])) OR "Homeopathy"[Mesh]) OR "Acupuncture"[Mesh]) OR "Diet"[Mesh]) AND "Scoliosis"[Mesh] and we found 68 papers; after reviewing the titles, 13 were considered of interest; looking at the abstracts 7 were maintained and retrieved in full text. We also searched: the abstracts of all SOSORT Meetings, from the first one in 2003 to 2010; the personal files and knowledge of all the authors; the papers retrieved with all the other searches listed in these Guidelines; the references sections of all retrieved papers. The selection criteria used in all these searches were: pertinence for the topic "Other conservative treatments"; presence of the abstract; numerical results in relation to scoliosis; retrievability in full text; all languages.

Results

When looking at other conservative approaches beyond Physiotherapeutic Specific Exercises, some case reports of improvement of scoliosis with mobilisation techniques applied as a stand-alone treatment have been reported in the short- (weeks) [277] and medium-term (months) [278]; the same has been done on mobilization together with other stabilising techniques in the medium- [279] and long-term (years) on spinal curve [280] and chest expansion [281]; a short-term case series has been reported as well [282]. Nevertheless, a systematic review was not able to conclude the effectiveness of manual treatment due to the lack of good studies [283]. Finally, there are no scientific studies on the therapeutic efficacy of shoe inserts (excluding heel lifts lifts), conventional and homeopathic medicines, acupuncture or specific dietary regimens for the correction of idiopathic scoliosis in adolescence.

\section{Recommendations on "Other conservative treatments"}

34. It is recommended that manual therapy (gentle, short-term mobilization, or releasing soft tissues techniques) is proposed only if associated with stabilization Physiotherapeutic Specific Exercises (SoR: B) (SoE: V) [283]

35. It is recommended that correction of real leg length discrepancy, if needed, is decided by a clinician specialized in conservative treatment of spinal deformities (SoR: B) (SoE: VI)

36. It is recommended that shoe inserts (excluding heel lifts), conventional and homeopathic medicines, acupuncture, or specific dietary regimens are not used to correct a spinal deformity (SoR: B) (SoE: VI)

\section{Respiratory function and exercises Methods}

In February 2011 we performed a search of Medline from its inception, with no language limitations. We used the terms ("Respiration"[Mesh]) AND "Scoliosis"[Mesh] and we found 182 papers; after reviewing the 
titles, 42 were considered of interest; looking at the abstracts 35 were maintained and retrieved in full text. We also searched: the abstracts of all SOSORT Meetings, from the first one in 2003 to 2010; the personal files and knowledge of all the authors; the papers retrieved with all the other searches listed in these Guidelines; the references sections of all retrieved papers. The selection criteria used in all these searches were: pertinence for the topic "Respiratory exercises"; presence of the abstract; numerical results in relation to scoliosis; retrievability in full text; all languages.

\section{Results}

A series of studies mainly in adolescents with scoliosis between 30 and $60^{\circ}$ have demonstrated various types of respiratory impairments in patients: abnormal ventilation patterns, mainly restrictive [284-286]; impaired function of respiratory muscles [284,286]; restriction $[285,287]$ and asymmetric motion of the chest wall, with localized alterations [288]; abnormal patterns of ventilation during exercise [289], similar to that seen in patients with severe COPD [290]. Among the possible causes, the deformity plays a role in terms of lateral flexion [284] (with some doubts [291]), vertebral rotation [292,293] and stiffness [285]; the sagittal diameter [292], overall dimensions [291,292] and stiffness [285] of the thoracic cage are important as well [294,295]

Exercise capacity appears impaired as well [284,296-298], but without a direct correlation with ventilatory limitations or abnormality in lung volumes [284,297,298]: determining factors appear to be deconditioning and lack of regular aerobic exercise $[297,298]$, as it can be shown also by lower limb muscle function [284] and also the severity of the scoliosis curve [296].

The natural history cohort followed-up 50 years by Weinstein seems to point to the conclusion that cardiorespiratory failure is not a common problem in the adult with adolescent idiopathic scoliosis [80], even if these results have been considered with some criticism, due to possible methodological flaws $[49,299]$. Pehrsson $[300,301]$ showed that cardiorespiratory failure occurs only in cases of severe scoliosis that had its onset in pre-puberty and with a strong tendency to progression, wherein vital capacity was the strongest indicator for possible respiratory failure. An interesting study was performed in adults with infantile-onset scoliosis, showing a correlation among treatment performed and resulting pulmonary function: those whose scoliosis resolved or was stabilized by non-operative means had normal pulmonary function; those who were managed by casting or bracing and underwent surgery after age 10 had acceptable pulmonary function; but those whose deformity necessitated early surgery had recurrence of deformity and diminished respiratory function [200].
All these studies point to the importance of performing general aerobic activities (including sport) and respiratory training to improve exercise capacity and respiratory muscles functioning, while decreasing deconditioning and thoracic stiffness. Nevertheless doubts could be raised in terms of asymmetric stress due to increased respiratory effort [302], and some old studies showed bad results $[303,304]$. Also, the role of Physiotherapeutic Specific Exercises can be discussed: while SOSORT experts suggested the use of respiratory exercises and education [305], one paper showed in adult scoliosis patients an increase in vital capacity and in chest wall expansion that would allow treatment of associated restrictive ventilatory diseases [306]; another paper demonstrated improvements of electrocardiographic parameters of right-heart stress [307]. If scoliosis is of very high degree, nocturnal nasal intermittent positive pressure ventilation (together with long-term oxygen therapy) can have a positive effect improving exercise capacity [308], survival rate [309], health-related quality of life and decreasing the hospitalization rate [310].

Bracing can impact pulmonary function, even if results are contradictory [311-315]. In scoliosis girls wearing a Boston-type brace a two-month aerobic training sustained or improved significantly the parameters of pulmonary function, while they were reduced in the control group with no exercises in Milwaukee brace [316]. In most of the studies, correction and surgical stabilization of the curve lead to only a slight improvement of pulmonary function, with some exceptions.

\section{Recommendations on "Respiratory function and exercises"}

37. It is recommended that, when needed, exercises to improve respiratory function are used (SoR: B) (SoE: V)

38. It is recommended during brace treatment to use exercises to improve respiratory function (SoR: B) (SoE: IV) [316]

39. It is recommended the use of Physiotherapeutic Specific Exercises to train regional respiratory strategies to promote the expansion and ventilation of specific lung compartments (SoR: B) (SoE: IV) [306]

\section{Sports activities Methods}

In February 2011 we performed a search of Medline from its inception, with no language limitations. We used the terms ("Sports"[Mesh]) AND "Scoliosis"[Mesh] and we found 105 papers; after reviewing the titles, 24 were considered of interest; looking at the abstracts 11 were maintained and retrieved in full text. We also searched: the abstracts of all SOSORT Meetings, from the first one in 2003 to 2010; the personal files and knowledge of all the authors; the papers retrieved with all the other searches listed in these Guidelines; the 
references sections of all retrieved papers. The selection criteria used in all these searches were: pertinence for the topic "Sports activities"; presence of the abstract; numerical results in relation to scoliosis; retrievability in full text; all languages.

\section{Results}

It has been suggested that general sports activities can be an active counterpart of Physiotherapeutic Specific Exercises [256]. Even if some confusion seems to remain in the literature between general sport activities and Physiotherapeutic Specific Exercises [317,318], their different role may be understood by looking at gross specific differences: Physiotherapeutic Specific Exercises are developed to purposely face scoliosis impairments and biomechanics [305], while the goal of sport activities is to either obtain agonistic results or improve fitness and wellness; moreover, Physiotherapeutic Specific Exercises work explicitly on the spinal muscles and posture control $[217,272,305,319]$, while sports activities on the big muscles related with limb movements. Nevertheless an interaction and overlap between the two types of physical activities exists and can be recognized. In particular, the specific social and educational role of sports activities in terms of play, either at or outside school, should never be neglected, since patients with scoliosis should play "the same as and even more than others" [2]. It has been highlighted how psychological and social aspects are related to the patient's negative image of his or her own body [320]: physical activity allows patients to work on these aspects and to stay involved with their peer group, particularly but not only during physical education at school.

Participating in various types of sports activities doesn't seem to affect the presence or degree of scoliosis [317]. Scoliotic patients prefer to practice sports like gymnastics (usually started before discovering scoliosis) [321,322]: this seems to be linked to a higher prevalence of joint laxity than controls [322]. Delay in menarche and generalized joint laxity are common in rhythmic gymnastic trainees as well, and a 10-fold higher incidence of scoliosis was found in this group (12\%) than in normal controls (1.1\%) [323]: a "dangerous triad" has been hypothesized, including generalized joint laxity, delayed maturity, and asymmetric spinal loading. Similarly, an increased incidence of scoliosis has been reported in ballet dancers (24\%) [324], and a separate etiology for ballet and rhythmic gymnastics than in adolescent idiopathic scoliosis has been hypothesized [325]. However, in a pair of 13.5-year-old female monozygotic twins who were high-level athletes in synchronized swimming, only one showed a 32 degrees thoracolumbar curve: this seems to suggest that factors other than genetics and sport activities play important roles [326].
Looking at other sports, even if swimming has been proposed traditionally as a good sport activity for scoliosis (and even prescribed by some physicians as a treatment), a $6.9 \%$ incidence of scoliosis, 3.5 -fold that in normal controls, has been reported in swimmers [327]. There are no papers at all looking at asymmetric sports, traditionally blamed, but without any scientific evidence.

Adolescents with double major curves practice more sports activities than those with a single major curve, but both groups less than normal controls: it has been hypothesised that the first scoliosis group can be less subject to scoliosis-related biomechanical repercussions leading to a better balance control [321]. Over the long term, patients with important idiopathic scoliosis suffer impairment of their sports activities compared with agematched controls, due to functional impairment and back pain. Sports activity is not more restricted after extended spinal fusion than it is after non-operative treatment [328]. In this respect, the Scoliosis Research Society surgeons return patients to noncontact sports between 6 months and 1 year post-operatively, while contact sports were generally withheld until 1 year after surgery; close to $20 \%$ of respondents required, and $35 \%$ suggested, that patients never return to collision sports. Twenty percent of surgeons reported having notable adverse outcomes attributed to athletic activity after surgery [275].

\section{Recommendations on "Sports activities"}

40. It is recommended that sports is not prescribed as a treatment for idiopathic scoliosis (SoR: C) (SoE: III) [317,321-324,326,327]

41. It is recommended that general sports activities are performed because of the specific benefits they offer to patients in terms of psychological, neuromotor and general organic well-being (SoR: B) (SoE: V)

42. It is recommended that, during all treatment phases, physical education at school is continued. Based on the severity of the curve and progression of the deformity and the opinion of a clinician specialized in conservative treatment of spinal deformities, restrictions may be placed on practicing certain types of sports activities (SoR: B) (SoE: V)

43. It is recommended that sports activities are continued also during brace treatment because of the physical (aerobic capacity) and psychological benefits these activities provide (SoR: B) (SoE: IV) [316]

44. It is recommended that, during brace treatment, contact or highly dynamic sport activities are performed with caution (SoR: B) (SoE: VI)

45. It is recommended that competitive activities that greatly mobilize the spine are avoided in patients with scoliosis at high risk of progression (SoR: C) (SoE: III) [284-287,317,322-324] 


\section{Assessment}

SOSORT has published in Scoliosis Journal a Consensus Paper titled "Methodology of evaluation of morphology of the spine and the trunk in idiopathic scoliosis and other spinal deformities-6th SOSORT consensus paper" [329]: this can serve as reference for specific insights.

Since scoliosis is diagnosed as idiopathic only by exclusion, it is mandatory at the first evaluation to collect family and personal clinical history and perform a full medical and neurological exam [329].

The main evaluation test in the clinical examination of patients with scoliosis is the Adam's forward bending test. A positive result to the test is pathognomic for scoliosis [330]. The test's positive predictive value varies since it is proportional to the degree of curvature and depends on operator experience [331].

The Scoliometer [332,333] measures the hump appearing as a consequence of the Adam's test: it is an evaluation tool that has proven highly useful. The Scoliometer measures the angle of trunk inclination (ATI, or ATR-Angle of Trunk Rotation) and has a high interobserver reproducibility, which permits the determination of cut-off points above which a radiographic study is indicated. It has a sensitivity of about $100 \%$ and a specificity of about $47 \%$ when an ATI angle of $5^{\circ}$ is chosen. At an ATI angle of $7^{\circ}$ sensitivity drops to $83 \%$ but specificity rises to $86 \%[28,334,335]$. While $7^{\circ}$ can be considered a good cut-off in a surgical setting, when prevention is desired through a good conservative approach, $5^{\circ}$ is a better cut-off.

Measurement of the hump is another instrument that can provide a further parameter of evaluation and differs from the Scoliometer in that it measures the height of the difference between curve concavity and convexity [89,336]. A cut-off point of $5 \mathrm{~mm}$ has been defined as significant for measuring back hump [336,337], and the reliability of this measurement has been reported $[89,334]$. A new instrument demonstrating high reproducibility has also been recently tested [338].

Being aesthetics a major concern for AIS patients [42], a specific assessment of trunk asymmetries should be used. The TRACE scale has been recently proposed and validated: it's a 12 point scale based on a visual assessment of shoulders, scapulae, waist and hemithorax asymmetries. Intra-rater repeatability was fair, being the minimum significant change three out of twelve, while inter-raters was poor being the minimum significant change four [88]. Also the self-evaluation by patients is very important in this respect, and validated scales like the Walter-Reed and TAPS have been proposed [339-342].

Quality of life (QoL) issues and disability are other main points to be considered in the treatment of IS patients [42]. A series of instruments (questionnaires) have been proposed in these years to evaluate QoL, starting for the first one that almost constitutes a standard, the SRS-22 [343-346]. Nevertheless, for clinical everyday conservative use the SRS-22 shows some limits, and other questionnaires have been developed like the BrQ [163,347-350] and the BSSQ [347,351-354].

The sagittal profile of the spine is frequently modified in scoliosis patients, and a sagittal measurement is recommended. Many different tools exist, like the plumbline, the Inclimed and the Arcometer [355-357].

Radiographic examination remains the reference standard: it is important to use one of the clinical cut-off points mentioned above (ATI or hump), before ordering a radiographic study, and during regular follow-up to reduce the burden of radiations [329]. Cobb angle measurements on the same radiographic image had an intra- and inter-observer variability of $3-5^{\circ}$ and $6-7^{\circ}$, respectively [358]; this classically reported error increases when the postural, and even diurnal changes in different exams are considered [358,359]. Radiographic measurement of the vertebral rotation using Perdriolle's torsiometer has been shown to be reproducible [360]. Based on the same principle, use of Raimondi's tables or ruler makes measurement easier and slightly more reproducible [361].

In infantile idiopathic scoliosis frontal plane radiographs a very important measurement has been proposed by Mehta: the rib-vertebra angle, that provide a prognostic factor allowing the examiner to distinguish between evolving and resolving scoliosis $[111,362,363]$.

The radiographic exam of the sagittal plane is important, but it has inherent difficulties due to the need to move the arm from the anatomical position to show the spine [357,364-366]: as a consequence, after performing it for diagnostic purposes, surface measurements can substitute it in follow-up of the patients [329,367,368].

The Risser sign [369] constitutes a further parameter for radiographic evaluation and is useful in indicating the patient's growth status, since Risser grading can be done using the same radiographic film to evaluate the scoliosis [128,370-372]. Other essential parameters to be considered are radiographic maturity of the ring apophyses (annular apophyses), appearance of menarche in girls, and Tanner staging [329]. Other diagnostic imaging procedures are in use in idiopathic scoliosis, like various radiographic technique beyond classical projections [373], MRI [373,374], neurophysiological exams [375]. Nevertheless, beyond their importance in the surgical setting, in the everyday use for conservative purposes, these techniques are not supported by the actual evidence, unless there are symptoms and signs of neurological compromise: only in these cases, in fact, a specific diagnosis is useful [376]. 
"Hot" topics of research that are almost ready to enter in the everyday clinical world and that will presumably be addressed in a few years with the next edition of these Guidelines include:

- Surface topography measurements, that have been widely used for research purposes in these years, but only recently are apparently entering the clinical everyday world [329,367,368]. Esthetics and sagittal plane evaluations could presumably become everyday clinics quite rapidly.

- Genetic evaluation [Ogilvie: 123-126]. Nevertheless, prudence is advised in using these tools to decide if to treat or not patients: in fact, moving from research, even if performed in wide samples of some hundreds of patients, to the general population requires caution.

Finally, a key point to be considered in the assessment of idiopathic scoliosis is screening: through an initial general surface measurement, and a subsequent selected clinical expert evaluation to eventually reach a final radiographic exam, the deformity can be detected early and treated to avoid progression. Even if doubts have been raised, screening for idiopathic scoliosis in asymptomatic adolescents is to be recommended [377]. SOSORT has published in Scoliosis Journal a Consensus Paper titled "SOSORT consensus paper: school screening for scoliosis: Where are we today?"[377]: this can serve as reference for specific insights.

\section{Recommendations}

46. School screening programs are recommended for the early diagnosis of idiopathic scoliosis (SoR: B) (SoE: IV)

47. It is recommended that, every time they evaluate children aged from 8 to 15 years, pediatricians, general practitioners and sports physicians perform the Adam's test for scoliosis screening purposes, using the Scoliometer (SoR: A) (SoE: V)

48. It is recommended that the Adam's test use is spread in the school community and among all people that are engaged in the health of children (parents included) (SoR: B) (SoE: V)

49. It is recommended that diagnostic evaluation is carried out by clinicians specialized in spinal deformities (SoR: B) (SoE: IV)

50. It is recommended that patients are always examined by the same clinicians specialized in spinal deformities. In settings in which this is not possible, it is recommended regular standardization and validation processes of the methods used (SoR: B) (SoE: IV)

51. It is recommended for clinical follow-up the use of validated assessment methods and standard clinical data collection forms (SoR: A) (SoE: V)
52. It is recommended that the assessment include pathologic, cosmetic, psychological, functional and family aspects (SoR: B) (SoE: V)

53. It is recommended that the sagittal alignment of the spine is evaluated (SoR: A) (SoE: V)

54. It is recommended the Scoliometer and Humpmeter for clinical evaluation and follow-up of patients (SoR: B) (SoE: V)

55. It is recommended during growth that clinical follow-up examinations are performed at least twice a year, a part periods of rapid growth (pubertal spurt, first three years of life) (SoR: B) (SoE: V)

56. It is recommended not to perform $\mathrm{x}$-rays if the Adam's test is negative and the Scoliometer value is below $5^{\circ}$, unless otherwise justified in the opinion of a clinician specialized in conservative treatment of spinal deformities (SoR: B) (SoE: IV)

57. It is recommended that the decision whether to perform a radiographic study should be made by a physician specialized in spinal deformities (SoR: A) (SoE: V)

58. It is recommended that frontal radiographic studies are made postero-anteriorly, using digital films with a ratio $\mathrm{x}$-rays, including visualization of the femoral heads and protection of the gonads, in any standing position without the use of support aids or indication of correct posture, unless otherwise justified in the opinion of a clinician specialized in spinal deformities (SoR: A) (SoE: IV)

59. It is recommended that curve magnitude is measured using the Cobb method (SoR: A) (SoE: V)

60. It is recommended that vertebral rotation is measured on the apical vertebra using either the Perdriolle torsiometer or the Raimondi tables/ruler (SoR: B) (SoE: IV)

61 . It is recommended that the first and last radiographic evaluation include also a standing lateral view (SoR: A) (SoE: V)

62. On radiographic lateral view, the patient's upper extremities should be placed in a position to uncover the upper thoracic spine. The recommended positions comprise: (1) $45^{\circ}$ angle flexion of the arms, elbows extended and hands resting on a support to preserve the sagittal curvature of the spine, (2) the arms crossed over the breasts, (3) the hand resting on the ipsilateral shoulder without pressing it (SoR: B) (SoE: IV)

63. To reduce the invasiveness of follow-up, it is recommended that no more than 1 radiographic study per year should be performed, unless it is truly necessary and is decided by a clinician specialized in spinal diseases (SoR: B) (SoE: IV) 
Table 8 Strength of Evidence of the approved Recommendations

\begin{tabular}{|c|c|c|c|c|c|c|c|}
\hline & I & II & III & IV & V & VI & Total \\
\hline Bracing & 0 & 0 & 2 & 7 & 8 & 3 & 20 \\
\hline Specific exercises to prevent scoliosis progression during growth & 0 & 1 & 2 & 0 & 1 & 4 & 8 \\
\hline Specific exercises during brace treatment and surgical therapy & 0 & 1 & 1 & 2 & 1 & 0 & 5 \\
\hline Other conservative treatments & 0 & 0 & 0 & 0 & 1 & 2 & 3 \\
\hline Respiratory function and exercises & 0 & 0 & 0 & 2 & 1 & 0 & 3 \\
\hline Sports activities & 0 & 0 & 2 & 1 & 2 & 1 & 6 \\
\hline Assessment & 0 & 0 & 0 & 8 & 12 & 0 & 20 \\
\hline Total & 0 & 2 & 7 & 20 & 26 & 10 & 65 \\
\hline
\end{tabular}

Table 9 Strength of Recommendations

\begin{tabular}{|c|c|c|c|c|c|}
\hline & A & B & C & D & Total \\
\hline Bracing & 4 & 15 & 1 & 0 & 20 \\
\hline Specific exercises to prevent scoliosis progression during growth & 0 & 8 & 0 & 0 & 8 \\
\hline Specific exercises during brace treatment and surgical therapy & 0 & 5 & 0 & 0 & 5 \\
\hline Other conservative treatments & 0 & 3 & 0 & 0 & 3 \\
\hline Respiratory function and exercises & 0 & 3 & 0 & 0 & 3 \\
\hline Sports activities & 0 & 4 & 2 & 0 & 6 \\
\hline Assessment & 9 & 11 & 0 & 0 & 20 \\
\hline Total & 13 & 49 & 3 & 0 & 65 \\
\hline
\end{tabular}

64. To reduce the invasiveness of follow-up, it is recommended that the least number of projections is made on radiographic studies (SoR: A) (SoE: V)

65. It is recommended that all idiopathic scoliosis patients, even if not treated, are regularly followed-up (SoR: A) (SoE: V)

\section{Conclusions and future research needs}

These Guidelines represent a significant improvement when compared to the previous experiences produced either internationally by SOSORT or nationally by other groups [1-4,378]. They have been a big effort of the Commission and the Society to paint the actual situation in this field, starting from the actual evidence, and trying to fill at best all the gray areas not covered by the literature, through the well experimented SOSORT Consensus methodology [38,42,101,114,130,305,329,379].

Like always, Guidelines offers an overview of the evidence in a specific field, and consequently give insights to researchers on which area should be studied more. Looking at Tables 8 and 9, that resume the final grading of the Recommendations in terms of Strength of Evidence and Strength of Recommendations respectively, it is possible to understand the already underlined lack of research in general in this specific area [99,100,260,380]: no evidences of strength level I, very few of level II.
We invite researchers to join this effort, and clinicians to develop good research strategies allowing us the collection of useful data and new evidence.

\section{Additional material}

Additional file 1: Appendix-Methods. This file contains a complete and accurate description of the methodology followed during of these Guidelines development. It also includes contributions of the single authors, as well as explicative tables.

\section{Acknowledgements}

We wish to thanks all participants to this work, that have been listed (if they agreed) in the Additional File 1-Appendix.

There has been no funding for this project, that has been developed on a voluntary basis by the Commission Members.

\section{Author details}

${ }^{1}$ Physical and Rehabilitation Medicine, University of Brescia, Italy. ${ }^{2}$ Don Gnocchi Foundation, Milan, Italy. ${ }^{3}$ ISICO (Italian Scientific Spine Institute), Milan, Italy. ${ }^{4}$ Orthopaedics and Traumatology Division, Bambino Gesù Children's Hospital, Institute of Scientific Research, Piazza San Onofrio 4, 00165, Rome, Italy. 'Department of Orthopaedics, Catholic University of the Sacred Heart, University Hospital 'Agostino Gemelli', L.go F. Vito, 1-00168 Rome, Italy. 'Sainte Justine Hospital, University of Montreal, Canada. ${ }^{7}$ Clinique du Parc, Lyon, France. ${ }^{8}$ Department of Rehabilitation, Medical University of Silesia and University Hospital, Katowice, Poland. ${ }^{9}$ Department of Trauma and Orthopaedics, "Tzanio" General Hospital, Tzani and Afendouli 1 st, Piraeus 18536, Greece. ${ }^{10}$ Rosalind Franklin University of Medicine and Science, North Chicago, Illinois, 60064, USA. ${ }^{11}$ Spine Disorders Unit, 
Department of Pediatric Orthopedics and Traumatology, University of Medical Sciences, Poznan, Poland. ${ }^{12}$ Department of Orthopaedic Surgery, Saitama Medical Center, Saitama Medical University, Japan. ${ }^{13}$ Cochrane Review Group on Drugs and Alcohol. Department of Epidemiology. Lazio Region. Via di Santa Costanza, 53. 00198 Rome. Italy. ${ }^{14}$ National Scoliosis Foundation, Boston, USA. ${ }^{15}$ Spondylos Laser Spine Lab, Orthopaedic Facility and Rehabilitation Center, 74, Messogion Ave, 115 27, Athens, Greece. ${ }^{16}$ Institut Elena Salvá. Vía Augusta 185. 08021 Barcelona, Spain. ${ }^{17}$ Boston Brace Co., Boston, USA. ${ }^{18}$ Gesundheitsforum Nahetal. Alzeyer Str. 23. D-55457 Gensingen, Germany.

\section{Authors' contributions}

SN prepared all versions of the document collating all suggestions; proposed, and made the final version of methodology; prepared all versions of flow-charts collating all suggestions. AGA reviewed and approved methodology; revised the initial document; contributed to the development of the clinical practice flow-charts. LA reviewed and approved methodology; revised the initial document; contributed to the development of the clinical practice flow-charts. $A B C$ reviewed and approved methodology; contributed to the development of the clinical practice flow-charts. JCDM reviewed and approved methodology; revised the initial document; contributed to the development of the clinical practice flow-charts. JD revised the initial document; contributed to the development of the clinical practice flowcharts. TBG revised the initial document; contributed to the development of the clinical practice flow-charts. PK approved the flow-charts. TK reviewed and approved methodology; revised the initial document; contributed to the development of the clinical practice flow-charts. TM contributed to the development of the clinical practice flow-charts. SM reviewed and approved methodology; made the final methodological review of the manuscript. JOB made the final practical review of the manuscript. DP reviewed and approved methodology; revised the initial document. MaRi reviewed and approved methodology; revised the initial document; contributed to the development of the clinical practice flow-charts. CHR revised the initial document; contributed to the development of the clinical practice flowcharts. MiRo reviewed and approved methodology; revised the initial document. JHW reviewed and approved methodology; revised the initial document. MV reviewed and approved methodology; revised the initial document. HRW approved the flow-charts. FZ reviewed and approved methodology; revised the initial document; contributed to the development of the clinical practice flow-charts. All authors read and approved the final manuscript.

\section{Competing interests}

All Commission Members are physicians, orthothists and physiotherapists who earn from their own work. The conflict of interests declared by the authors are:

Stefano Negrini has a stock of ISICO (Italian Scientific Spine Institute), Italy Dimitris Papadopoulos is the major shareholder of Spondylos Laser Spine Lab, Greece.

Manuel Rigo is advisor of Ortholutions, Germany.

Charles H Rivard is consultant to Spinecorporation Ltd, UK.

Michele Romano has a stock of ISICO (Italian Scientific Spine Institute), Italy Hans-Rudolf Weiss is advisor of Koob-Scolitech, Abtweiler, Germany. James H. Wynne is an employee of Boston Brace Corp., USA: No other conflict of interests have been declared.

Received: 28 December 2011 Accepted: 20 January 2012 Published: 20 January 2012

\section{References}

1. Weiss H-R, Negrini S, Rigo M, Kotwicki T, Hawes M, Grivas T, Maruyama T, Landauer F, committee Sg: Indications for conservative management of scoliosis (guidelines). Scoliosis 2006, 1(1):5.

2. Negrini $S$, Aulisa $L$, Ferraro $C$, Fraschini $P$, Masiero $S$, Simonazzi $P$, Tedeschi C, Venturin A: Italian guidelines on rehabilitation treatment of adolescents with scoliosis or other spinal deformities. Eura Medicophys 2005, 41(2):183-201.

3. Scoliose structurale évolutive (dont l'angle est égal ou supérieur à $25^{\circ}$ ) jusqu'à maturation rachidienne. [http://www.has-sante.fr].

4. Kotwicki T, Durmala J, Czaprowski D, Glowacki M, Kolban M, Snela S, Sliwinski Z, Kowalski IM: Conservative management of idiopathic scoliosis-guidelines based on SOSORT 2006 Consensus. Ortop Traumatol Rehabil 2009, 11(5):379-395.

5. Vasiliadis ES, Grivas TB, Kaspiris A: Historical overview of spinal deformities in ancient Greece. Scoliosis 2009, 4(1):6.

6. Grivas TB, Burwell GR, Vasiliadis ES, Webb JK: A segmental radiological study of the spine and rib-cage in children with progressive Infantile Idiopathic Scoliosis. Scoliosis 2006, 1:17.

7. Grivas TB, Vasiliadis ES, Rodopoulos G, Bardakos N: The role of the intervertebral disc in correction of scoliotic curves. A theoretical model of idiopathic scoliosis pathogenesis. Stud Health Technol Inform 2008, 140:33-36.

8. Grivas TB, Vasiliadis ES, Rodopoulos G: Aetiology of Idiopathic Scoliosis. What have we learned from school screening? Stud Health Technol Inform 2008, 140:240-244.

9. Nachemson A, Sahlstrand T: Etiologic factors in adolescent idiopathic scoliosis. Spine 1977, 1(2):176-184.

10. Burwell RG, Cole AA, Cook TA, Grivas TB, Kiel AW, Moulton A, Thirlwall AS, Upadhyay SS, Webb JK, Wemyss-Holden SA, et al: Pathogenesis of idiopathic scoliosis. The Nottingham concept. Acta Orthop Belg 1992, 58(Suppl 1):33-58.

11. Grivas TB, Burwell RG, Purdue M, Webb JK, Moulton A: A segmental analysis of thoracic shape in chest radiographs of children. Changes related to spinal level, age, sex, side and significance for lung growth and scoliosis. J Anat 1991, 178:21-38.

12. Burwell RG, Aujla RK, Grevitt MP, Dangerfield PH, Moulton A, Randell TL, Anderson SI: Pathogenesis of adolescent idiopathic scoliosis in girls-a double neuro-osseous theory involving disharmony between two nervous systems, somatic and autonomic expressed in the spine and trunk: possible dependency on sympathetic nervous system and hormones with implications for medical therapy. Scoliosis 2009, 4:24.

13. Grivas TB, Samelis P, Chadziargiropoulos T, Polyzois B: Study of the rib cage deformity in children with 10 degrees-20 degrees of Cobb angle late onset idiopathic scoliosis, using rib-vertebra angles-aetiologic implications. Stud Health Technol Inform 2002, 91:20-24.

14. Weinstein SL: Natural history. Spine 1999, 24(24):2592-2600.

15. Grivas TB, Dangas S, Polyzois BD, Samelis P: The Double Rib Contour Sign (DRCS) in lateral spinal radiographs: aetiologic implications for scoliosis. Stud Health Technol Inform 2002, 88:38-43.

16. Stagnara P: Les deformations du rachis. Paris: Masson; 1985.

17. Perdriolle R: La scoliose. Son ètude tridimensionelle. Maloine Edieur, Paris 1979.

18. Dubousset J: Importance of the three-dimensional concept in the treatment of scoliotic deformities. In International Symposium on 3D Scoliotic deformities joined with the VIlth International Symposium on Spinal Deformity and Surface Topography. Edited by: Dansereau J. Germany: Gustav Fisher Verlag; 1992:302-311.

19. Kotwicki T, Kinel E, Stryla W, Szulc A: Discrepancy in clinical versus radiological parameters describing deformity due to brace treatment for moderate idiopathic scoliosis. Scoliosis 2007, 2:18.

20. Xiong B, Sevastik JA, Hedlund R, Sevastik B: Radiographic changes at the coronal plane in early scoliosis. Spine (Phila Pa 1976) 1994, 19(2):159-164.

21. Burwell RG, James NJ, Johnson F, Webb JK, Wilson YG: Standardised trunk asymmetry scores. A study of back contour in healthy school children. J Bone Joint Surg Br 1983, 65(4):452-463.

22. Brooks H, Azen S, Gerberg E, Brooks R, Chan L: Scoliosis: a prospective epidemiological study. Journal of Bone and Joint Surgery 1975, 57:968-972.

23. Wong HK, Hui JH, Rajan U, Chia HP: Idiopathic scoliosis in Singapore schoolchildren: a prevalence study 15 years into the screening program. Spine 2005, 30(10):1188-1196.

24. Grivas TB, Vasiliadis E, Mouzakis V, Mihas C, Koufopoulos G: Association between adolescent idiopathic scoliosis prevalence and age at menarche in different geographic latitudes. Scoliosis 2006, 1:9.

25. Dickson RA: Scoliosis in the community. Br Med J (Clin Res Ed) 1983, 286(6379):1745.

26. Soucacos PN, Soucacos PK, Zacharis KC, Beris AE, Xenakis TA: Schoolscreening for scoliosis. A prospective epidemiological study in northwestern and central Greece. J Bone Joint Surg Am 1997, 79(10):1498-1503.

27. Pin LH, Mo LY, Lin L, Hua LK, Hui HP, Hui DS, Chang BD, Chang YY, Yuan L: Early diagnosis of scoliosis based on school-screening. J Bone Joint Surg Am 1985, 67(8):1202-1205. 
28. Huang SC: Cut-off point of the Scoliometer in school scoliosis screening. Spine (Phila Pa 1976) 1997, 22(17):1985-1989.

29. Nissinen M, Heliovaara M, Ylikoski M, Poussa M: Trunk asymmetry and screening for scoliosis: a longitudinal cohort study of pubertal schoolchildren. Acta Paediatr 1993, 82(1):77-82.

30. Willner $S, U$ den $A$ : A prospective prevalence study of scoliosis in Southern Sweden. Acta Orthop Scand 1982, 53(2):233-237.

31. Laulund T, Sojbjerg JO, Horlyck E: Moire topography in school screening for structural scoliosis. Acta Orthop Scand 1982, 53(5):765-768.

32. Morais T, Bernier M, Turcotte F: Age- and sex-specific prevalence of scoliosis and the value of school screening programs. Am J Public Health 1985, 75(12):1377-1380.

33. Yawn BP, Yawn RA, Hodge D, Kurland M, Shaughnessy WJ, Ilstrup D, Jacobsen SJ: A population-based study of school scoliosis screening. Jama 1999, 282(15):1427-1432.

34. Gore DR, Passehl R, Sepic S, Dalton A: Scoliosis screening: results of a community project. Pediatrics 1981, 67(2):196-200.

35. Rogala EJ, Drummond DS, Gurr J: Scoliosis: incidence and natural history. A prospective epidemiological study. J Bone Joint Surg Am 1978, 60(2):173-176.

36. Shands AR Jr, Eisberg HB: The incidence of scoliosis in the state of Delaware; a study of 50,000 minifilms of the chest made during a survey for tuberculosis. J Bone Joint Surg Am 1955, 37-A(6):1243-1249.

37. Koukourakis I, Giaourakis G, Kouvidis G, Kivernitakis E, Blazos J, Koukourakis M: Screening school children for scoliosis on the island of Crete. J Spinal Disord 1997, 10(6):527-531.

38. Grivas TB, Wade MH, Negrini S, O'Brien JP, Maruyama T, Hawes MC, Rigo M, Weiss HR, Kotwicki T, Vasiliadis ES, et al: SOSORT consensus paper: school screening for scoliosis. Where are we today? Scoliosis 2007, 2:17.

39. Grivas TB, Vasiliadis E, Savvidou O, Mouzakis V, Koufopoulos G: Geographic latitude and prevalence of adolescent idiopathic scoliosis. Stud Health Technol Inform 2006, 123:84-89.

40. Parent S, Newton PO, Wenger DR: Adolescent idiopathic scoliosis: etiology, anatomy, natural history, and bracing. Instr Course Lect 2005, 54:529-536.

41. Lonstein JE: Scoliosis: surgical versus nonsurgical treatment. Clin Orthop Relat Res 2006, 443:248-259.

42. Negrini S, Grivas TB, Kotwicki T, Maruyama T, Rigo M, Weiss HR: Why do we treat adolescent idiopathic scoliosis? What we want to obtain and to avoid for our patients. SOSORT 2005 Consensus paper. Scoliosis 2006, 1:4.

43. Kindsfater K, Lowe T, Lawellin D, Weinstein D, Akmakjian A: Levels of platelet calmodulin for the prediction of progression and severity of AIS. Journal of Bone and Joint Surgery 1994, , 76-A: 1186-1192.

44. Aulisa L, Papaleo P, Pola E, Angelini F, Aulisa AG, Tamburrelli FC, Pola P, Logroscino CA: Association between IL-6 and MMP-3 gene polymorphisms and adolescent idiopathic scoliosis: a case-control study. Spine (Phila Pa 1976) 2007, 32(24):2700-2702.

45. Negrini A, Parzini S, Negrini MG, Romano M, Atanasio S, Zaina F, Negrini S: Adult scoliosis can be reduced through specific SEAS exercises: a case report. Scoliosis 2008, 3:20.

46. Aebi M: The adult scoliosis. Eur Spine J 2005, 14(10):925-948.

47. Bunnell WP: The natural history of idiopathic scoliosis. Clin Orthop Relat Res 1988, 229: 20-25.

48. Weinstein SL, Dolan LA, Cheng JC, Danielsson A, Morcuende JA: Adolescent idiopathic scoliosis. Lancet 2008, 371(9623):1527-1537.

49. Hawes MC: Health and function of patients with untreated idiopathic scoliosis. Jama 2003, 289(20):2644, author reply 2644-2645.

50. Zmurko MG, Mooney JF, Podeszwa DA, Minster GJ, Mendelow MJ, Guirgues A: Inter- and intraobserver variance of Cobb angle measurements with digital radiographs. J Surg Orthop Adv 2003, 12(4):208-213.

51. Pruijs JE, Hageman MA, Keessen W, van der Meer R, van Wieringen JC Variation in Cobb angle measurements in scoliosis. Skeletal Radiol 1994, 23(7):517-520.

52. Ylikoski M, Tallroth K: Measurement variations in scoliotic angle, vertebral rotation, vertebral body height, and intervertebral disc space height. J Spinal Disord 1990, 3(4):387-391.

53. Carman DL, Browne RH, Birch JG: Measurement of scoliosis and kyphosis radiographs. Intraobserver and interobserver variation. J Bone Joint Surg Am 1990, 72(3):328-333.
54. Morrissy RT, Goldsmith GS, Hall EC, Kehl D, Cowie GH: Measurement of the Cobb angle on radiographs of patients who have scoliosis. Evaluation of intrinsic error. J Bone Joint Surg Am 1990, 72(3):320-327.

55. Goldberg MS, Poitras B, Mayo NE, Labelle H, Bourassa R, Cloutier R: Observer variation in assessing spinal curvature and skeletal development in adolescent idiopathic scoliosis. Spine 1988, 13(12):1371-1377.

56. Ponseti IV, Friedman B: Prognosis in idiopathic scoliosis. J Bone Joint Surg Am 1950, 32A(2):381-395.

57. Schulthess W: Die pathologie und Therapie der Ruckgratsverkrummungen.Edited by: Chirurgie HdO. Germany, Jena: Joachimsthal. G.; 1:1905-1907.

58. Winter R: Classification and Terminology. Moe's Textbook of Scoliosis and Other Spinal Deformities 1995, 39-43.

59. Lenke LG, Edwards CC, Bridwell KH: The Lenke classification of adolescent idiopathic scoliosis: how it organizes curve patterns as a template to perform selective fusions of the spine. Spine 2003, 28(20):S199-207.

60. Lenke LG, Betz RR, Clements D, Merola A, Haher T, Lowe T, Newton P, Bridwell KH, Blanke K: Curve prevalence of a new classification of operative adolescent idiopathic scoliosis: does classification correlate with treatment? Spine 2002, 27(6):604-611.

61. Lenke LG, Betz RR, Harms J, Bridwell KH, Clements DH, Lowe TG, Blanke K: Adolescent idiopathic scoliosis: a new classification to determine extent of spinal arthrodesis. J Bone Joint Surg Am 2001, 83-A(8):1169-1181.

62. King $\mathrm{H}$ : The selection of fusion levels in thoracic idiopathic scoliosis. $J$ Bone Joint Surg 1983, 65-A:1302-1313.

63. King HA: Selection of fusion levels for posterior instrumentation and fusion in idiopathic scoliosis. Orthop Clin North Am 1988, 19(2):247-255.

64. Rigo M: Intraobserver reliability of a new classification correlating with brace treatment. Pediatric Rehabilitation 2004, 7:63.

65. Rigo MD, Villagrasa M, Gallo D: A specific scoliosis classification correlating with brace treatment: description and reliability. Scoliosis 2009, 5(1):1

66. Lehnert-Schroth C: Three-Dimensional Treatment for Scoliosis. The Schroth Orthopedic Breathing System. A Physiotherapeutic Method to Improve Deformities of the Spine. Palo Alto (CA): The Martindale Press; 2007.

67. Weiss HR, Werkmann M: "Brace Technology" Thematic Series-The ScoliOlogiC(R) Cheneau light brace in the treatment of scoliosis. Scoliosis 2010, 5:19.

68. Weiss HR: "Brace technology" thematic series-the Gensingen brace in the treatment of scoliosis. Scoliosis 2010, 5:22.

69. Negrini A, Negrini S: The three-dimensional easy morphological (3-DEMO) classification of scoliosis, part II: repeatability. Scoliosis 2006, 1:23.

70. Negrini S, Negrini A: The three-dimensional easy morphological (3-DEMO) classification of scoliosis-Part III, correlation with clinical classification and parameters. Scoliosis 2007, 2:5

71. Negrini S, Negrini A, Atanasio S, Santambrogio GC: Three-dimensional easy morphological (3-DEMO) classification of scoliosis, part I. Scoliosis 2006, $1: 20$.

72. Duong L, Cheriet F, Labelle $H$ : Three-dimensional classification of spinal deformities using fuzzy clustering. Spine 2006, 31(8):923-930.

73. Poncet $\mathrm{P}$, Dansereau J, Labelle H: Geometric Torsion in Idiopathic Scoliosis: A Third 3D Analysis and a Proposal to a New Classification. Proceeding of the Second Biannual Meeting of the International Research Society of Spinal Deformities: 1998 Amsterdam: IOS; 1998, 122-125.

74. Sangole AP, Aubin CE, Labelle H, Stokes IA, Lenke LG, Jackson R, Newton P: Three-dimensional classification of thoracic scoliotic curves. Spine (Phila Pa 1976) 2009, 34(1):91-99.

75. Stokes IA, Sangole AP, Aubin CE: Classification of scoliosis deformity three-dimensional spinal shape by cluster analysis. Spine (Phila Pa 1976) 2009, 34(6):584-590.

76. Aulisa AG, Guzzanti V, Galli M, Perisano C, Falciglia F, Aulisa L: Treatment of thoraco-lumbar curves in adolescent females affected by idiopathic scoliosis with a progressive action short brace (PASB): assessment of results according to the SRS committee on bracing and nonoperative management standardization criteria. Scoliosis 2009, 4:21.

77. Negrini S, Negrini F, Fusco C, Zaina F: Idiopathic scoliosis patients with curves more than $45 \mathrm{Cobb}$ degrees refusing surgery can be effectively treated through bracing with curve improvements. Spine J 2011. 
78. Negrini S, Atanasio S, Fusco C, Zaina F: Effectiveness of complete conservative treatment for adolescent idiopathic scoliosis (bracing and exercises) based on SOSORT management criteria: results according to the SRS criteria for bracing studies-SOSORT Award 2009 Winner. Scoliosis 2009, 4:19.

79. Weiss HR, Weiss GM: Brace treatment during pubertal growth spurt in girls with idiopathic scoliosis (IS): a prospective trial comparing two different concepts. Pediatr Rehabil 2005, 8(3):199-206.

80. Weinstein SL, Dolan LA, Spratt KF, Peterson KK, Spoonamore MJ, Ponseti IV: Health and function of patients with untreated idiopathic scoliosis: a 50 year natural history study. Jama 2003, 289(5):559-567.

81. Mayo NE, Goldberg MS, Poitras B, Scott S, Hanley J: The Ste-Justine Adolescent Idiopathic Scoliosis Cohort Study. Part III: Back pain. Spine 1994, 19(14):1573-1581.

82. Goldberg MS, Mayo NE, Poitras B, Scott S, Hanley J: The Ste-Justine Adolescent Idiopathic Scoliosis Cohort Study. Part II: Perception of health, self and body image, and participation in physical activities. Spine 1994, 19(14):1562-1572

83. Danielsson AJ, Nachemson AL: Back pain and function 23 years after fusion for adolescent idiopathic scoliosis: a case-control study-part II. Spine 2003, 28(18):E373-383.

84. Danielsson AJ, Nachemson AL: Back pain and function 22 years after brace treatment for adolescent idiopathic scoliosis: a case-control studypart I. Spine 2003, 28(18):2078-2085, discussion 2086

85. Danielsson AJ, Wiklund I, Pehrsson K, Nachemson AL: Health-related quality of life in patients with adolescent idiopathic scoliosis: a matched follow-up at least 20 years after treatment with brace or surgery. Eur Spine J 2001, 10(4):278-288.

86. Weiss H: Scoliosis related pain in adults-treatment influences. Eur J Phys Med Rehab 1993, 3:91-94

87. Weiss H, Verres C, Lohschmidt K, El Obeidi N: Pain and scoliosis-is there any relationship? Orthop Prax 1998, 34:602-606.

88. Zaina F, Negrini S, Atanasio S: TRACE (Trunk Aesthetic Clinical Evaluation), a routine clinical tool to evaluate aesthetics in scoliosis patients: development from the Aesthetic Index (Al) and repeatability. Scoliosis 2009, 4(1):3.

89. Aulisa AG, Guzzanti V, Perisano C, Marzetti E, Menghi A, Giordano M Aulisa L: Correlation between Hump Dimensions and Curve Severity in Idiopathic Scoliosis before and after Conservative Treatment. Spine (Phila $\mathrm{Pa}$ 1976) 2011.

90. Negrini S, Romano M, Negrini A, Parzini S: End-growth final results of an effective conservative treatment: a retrospective case series. 4 th International Conference on Conservative Management of Spinal Deformities: 13-16 May 20072007 Boston: SOSORT (Society on Scoliosis Orthopaedic and Rehabilitation Treatment); 2007

91. Negrini S, Atanasio S, Zaina F, Romano M, Parzini S, Negrini A: End-growth results of bracing and exercises for adolescent idiopathic scoliosis. Prospective worst-case analysis. Stud Health Technol Inform 2008, 135:395-408

92. Sibilla P: Trent'anni di scoliosi. Lezione "non" magistrale. In Rachide \& Riabilitazione 2002. Volume 1. Edited by: Negrini S, Rainero G. Vigevano: Gruppo di Studio Scoliosi e patologie vertebrali; 2002:73-92.

93. Sibilla P: Il trattamento conservativo attivo della scoliosi idiopatica in Italia. In Le deformità vertebrali: stato dell'arte. Volume 2. Edited by: Negrini S, Sibilla P. Vigevano: Gruppo di Studio Scoliosi e patologie vertebrali; 2001:20-41.

94. Negrini S: The Evidence-Based ISICO Approach to Spinal Deformities. 1 edition. Milan, Boston: ISICO; 2007

95. Fowler PB: Evidence-based medicine. Lancet 1995, 346(8978):838.

96. White KL: Evidence-based medicine. Lancet 1995, 346(8978):837-838, author reply 840

97. Naylor CD: Grey zones of clinical practice: some limits to evidence-based medicine. Lancet 1995, 345(8953):840-842.

98. Sackett $\mathrm{DL}$, Rosenberg WM: The need for evidence-based medicine. $J R$ Soc Med 1995, 88(11):620-624.

99. Negrini S, Grivas TB: Introduction to the "Scoliosis" Journal Brace Technology Thematic Series: increasing existing knowledge and promoting future developments. Scoliosis 2010, 5(1):2.

100. Rigo MD, Grivas TB: "Rehabilitation schools for scoliosis" thematic series: describing the methods and results. Scoliosis 2010, 5:27.
101. Grivas TB, de Mauroy JC, Negrini S, Kotwicki T, Zaina F, Wynne JH, Stokes IA, Knott $P$, Pizzetti $P$, Rigo $M$, et al: Terminology-glossary including acronyms and quotations in use for the conservative spinal deformities treatment: 8th SOSORT consensus paper. Scoliosis 2010, 5:23.

102. Coillard C, Circo AB, Rivard CH: SpineCor treatment for Juvenile Idiopathic Scoliosis: SOSORT award 2010 winner. Scoliosis 2010, 5:25

103. Coillard C, Vachon V, Circo AB, Beausejour M, Rivard CH: Effectiveness of the SpineCor brace based on the new standardized criteria proposed by the scoliosis research society for adolescent idiopathic scoliosis. J Pediatr Orthop 2007, 27(4):375-379.

104. Wynne JH: The Boston Brace and TriaC systems. Disabil Rehabil Assist Technol 2008, 3(3):130-135

105. Veldhuizen AG, Cheung J, Bulthuis GJ, Nijenbanning G: A new orthotic device in the non-operative treatment of idiopathic scoliosis. Med Eng Phys 2002, 24(3):209-218.

106. de Mauroy JC, Fender P, Tato B, Lusenti P, Ferracane G: Lyon brace. Stud Health Technol Inform 2008, 135:327-340.

107. de Mauroy JC, Lecante C, Barral F, Daureu D, Gualerzi S, Gagliano R: The Lyon brace. Disabil Rehabil Assist Technol 2008, 3(3):139-145.

108. de Mauroy JC, Lecante C, Barral F: "Brace Technology" Thematic SeriesThe Lyon approach to the conservative treatment of scoliosis. Scoliosis 2011, 6(1):4.

109. Mammano S, Scapinelli R: Plaster casts for the correction of idiopathic scoliosis. Acta Orthop Belg 1992, 58(Suppl 1):81-84.

110. Risser JC: Scoliosis treated by cast correction and spine fusion. Clin Orthop Relat Res 1976, , 116: 86-94.

111. Mehta MH: Growth as a corrective force in the early treatment of progressive infantile scoliosis. J Bone Joint Surg Br 2005, 87(9):1237-1247.

112. Negrini S, Atanasio S, Negrini F, Zaina F, Marchini G: The Sforzesco brace can replace cast in the correction of adolescent idiopathic scoliosis: A controlled prospective cohort study. Scoliosis 2008, 3(1):15.

113. Negrini S, Marchini G: Efficacy of the Symmetric, Patient-oriented, Rigid, Three-dimensional, active (SPoRT) concept of bracing for scoliosis: a prospective study of the Sforzesco versus Lyon brace. Eura Medicophys 2006

114. Negrini S, Grivas TB, Kotwicki T, Rigo M, Zaina F: Guidelines on "Standards of management of idiopathic scoliosis with corrective braces in everyday clinics and in clinical research": SOSORT Consensus 2008. Scoliosis 2009, 4(1):2.

115. Bunnell WP: Selective screening for scoliosis. Clin Orthop Relat Res 2005, 434: 40-45.

116. Asher MA, Burton DC: Adolescent idiopathic scoliosis: natural history and long term treatment effects. Scoliosis 2006, 1(1):2.

117. Grivas TB, Dangas S, Samelis P, Maziotou C, Kandris K: Lateral spinal profile in school-screening referrals with and without late onset idiopathic scoliosis 10 degrees-20 degrees. Stud Health Technol Inform 2002, 91:25-31.

118. Rigo M, Quera-Salva G, Villagrasa M: Sagittal configuration of the spine in girls with idiopathic scoliosis: progressing rather than initiating factor. Stud Health Technol Inform 2006, 123:90-94.

119. Bagnall K: How can we achieve success in understanding the aetiology of AIS? Stud Health Technol Inform 2008, 135:61-74.

120. Bagnall KM: Using a synthesis of the research literature related to the aetiology of adolescent idiopathic scoliosis to provide ideas on future directions for success. Scoliosis 2008, 3:5.

121. Bagnall KM, Grivas TB, Alos N, Asher M, Aubin CE, Burwell RG, Dangerfield PH, Edouard T, Hill D, Lou E, et al: The International Research Society of Spinal Deformities (IRSSD) and its contribution to science. Scoliosis 2009, 4(1):28.

122. Grivas TB, Vasiliadis E, Malakasis M, Mouzakis V, Segos D: Intervertebral disc biomechanics in the pathogenesis of idiopathic scoliosis. Stud Health Technol Inform 2006, 123:80-83.

123. Ogilvie JW, Braun J, Argyle V, Nelson L, Meade M, Ward K: The search for idiopathic scoliosis genes. Spine (Phila Pa 1976) 2006, 31(6):679-681.

124. Miller NH: Idiopathic scoliosis: cracking the genetic code and what does it mean? J Pediatr Orthop 2011, 31(1 Suppl):S49-52.

125. Ogilvie JW: Update on prognostic genetic testing in adolescent idiopathic scoliosis (AIS). J Pediatr Orthop 2011, 31(1 Suppl):S46-48.

126. Ward K, Ogilvie JW, Singleton MV, Chettier R, Engler G, Nelson LM: Validation of DNA-based prognostic testing to predict spinal curve 
progression in adolescent idiopathic scoliosis. Spine (Phila Pa 1976) 2011, 35(25):E1455-1464

127. Peterson $L E$, Nachemson AL: Prediction of progression of the curve in girls who have adolescent idiopathic scoliosis of moderate severity. Logistic regression analysis based on data from The Brace Study of the Scoliosis Research Society. J Bone Joint Surg Am 1995, 77(6):823-827.

128. Little DG, Song KM, Katz D, Herring JA: Relationship of peak height velocity to other maturity indicators in idiopathic scoliosis in girls. $J$ Bone Joint Surg Am 2000, 82(5):685-693.

129. Lonstein JE, Carlson JM: The prediction of curve progression in untreated idiopathic scoliosis during growth. J Bone Joint Surg Am 1984, 66(7):1061-1071

130. Rigo M, Negrini S, Weiss H, Grivas T, Maruyama T, Kotwicki T: 'SOSORT consensus paper on brace action: TLSO biomechanics of correction (investigating the rationale for force vector selection)'. Scoliosis 2006, 1:11.

131. Negrini S, Minozzi S, Bettany-Saltikov J, Zaina F, Chockalingam N, Grivas TB, Kotwicki T, Maruyama T, Romano M, Vasiliadis ES: Braces for idiopathic scoliosis in adolescents. Spine (Phila Pa 1976) 35(13):1285-1293.

132. Negrini S, Minozzi S, Bettany-Saltikov J, Zaina F, Chockalingam N, Grivas TB, Kotwicki T, Maruyama T, Romano M, Vasiliadis ES: Braces for idiopathic scoliosis in adolescents. Cochrane Database Syst Rev 2010, 1: CD006850.

133. Nachemson AL, Peterson LE: Effectiveness of treatment with a brace in girls who have adolescent idiopathic scoliosis. A prospective, controlled study based on data from the Brace Study of the Scoliosis Research Society. J Bone Joint Surg Am 1995, 77(6):815-822.

134. Wong MS, Cheng JC, Lam TP, Ng BK, Sin SW, Lee-Shum SL, Chow DH, Tam SY: The effect of rigid versus flexible spinal orthosis on the clinical efficacy and acceptance of the patients with adolescent idiopathic scoliosis. Spine 2008, 33(12):1360-1365.

135. Rivard CH: Re: Wong MS, Cheng JC, Lam TP, et al. The effect of rigid versus flexible spinal orthosis on the clinical efficacy and acceptance of the patients with adolescent idiopathic scoliosis. Spine 2008;33:1360-5. Spine (Phila Pa 1976) 2008, 33(25):2837, author reply 2837-2838.

136. Richards BS, Bernstein RM, D'Amato CR, Thompson GH: Standardization of criteria for adolescent idiopathic scoliosis brace studies: SRS Committee on Bracing and Nonoperative Management. Spine 2005, 30(18):2068-2075, discussion 2076-2067.

137. Coillard C, Circo AB, Rivard CH: Effectiveness of the SpineCor brace based on the standardized criteria proposed by the S.R.S. for adolescent idiopathic scoliosis-up to date results. 6th International Conference on Conservative Management of Spinal Deformites: 2009; Lyon 2009, saa15.

138. Janicki JA, Poe-Kochert C, Armstrong DG, Thompson GH: A comparison of the thoracolumbosacral orthoses and providence orthosis in the treatment of adolescent idiopathic scoliosis: results using the new SRS inclusion and assessment criteria for bracing studies. J Pediatr Orthop 2007, 27(4):369-374.

139. Gammon SR, Mehlman CT, Chan W, Heifetz J, Durrett G, Wall EJ: A comparison of thoracolumbosacral orthoses and SpineCor treatment of adolescent idiopathic scoliosis patients using the Scoliosis Research Society standardized criteria. J Pediatr Orthop 2010, 30(6):531-538.

140. Zaborowska-Sapeta K, Kowalski IM, Kotwicki T, Protasiewicz-Faldowska H, Kiebzak W: Effectiveness of Cheneau brace treatment for idiopathic scoliosis: prospective study in 79 patients followed to skeletal maturity. Scoliosis 2011, 6(1):2.

141. Dolan LA, Weinstein SL: Surgical rates after observation and bracing for adolescent idiopathic scoliosis: an evidence-based review. Spine 2007, 32(19 Suppl):S91-S100.

142. Rigo M, Reiter C, Weiss HR: Effect of conservative management on the prevalence of surgery in patients with adolescent idiopathic scoliosis. Pediatr Rehabil 2003, 6(3-4):209-214.

143. Maruyama T, Kitagawa T, Takeshita K, Mochizuki K, Nakamura K: Conservative treatment for adolescent idiopathic scoliosis: can it reduce the incidence of surgical treatment? Pediatr Rehabil 2003, 6(3-4):215-219.

144. Weiss HR, Weiss G, Schaar HJ: Incidence of surgery in conservatively treated patients with scoliosis. Pediatr Rehabil 2003, 6(2):111-118.

145. Rowe DE, Bernstein SM, Riddick MF, Adler F, Emans JB, Gardner-Bonneau D: A meta-analysis of the efficacy of non-operative treatments for idiopathic scoliosis. J Bone Joint Surg Am 1997, 79(5):664-674.
146. Bunnell WP, MacEwen GD, Jayakumar S: The use of plastic jackets in the non-operative treatment of idiopathic scoliosis. Preliminary report. J Bone Joint Surg Am 1980, 62(1):31-38.

147. Montgomery F, Willner S: Prognosis of brace-treated scoliosis. Comparison of the Boston and Milwaukee methods in 244 girls. Acta Orthop Scand 1989, 60(4):383-385

148. Katz DE, Richards BS, Browne RH, Herring JA: A comparison between the Boston Brace and the Charleston bending brace in adolescent idiopathic scoliosis. Spine 1997, 22(12):1302-1312.

149. Howard A, Wright JG, Hedden D: A comparative study of TLSO, Charleston, and Milwaukee braces for idiopathic scoliosis. Spine 1998, 23(22):2404-2411.

150. Yrjonen T, Ylikoski M, Schlenzka D, Kinnunen R, Poussa M: Effectiveness of the Providence nighttime bracing in adolescent idiopathic scoliosis: a comparative study of 36 female patients. Eur Spine J 2006, 15(7):1139-1143

151. Negrini S, Marchini G: Efficacy of the symmetric, patient-oriented, rigid, three-dimensional, active (SPoRT) concept of bracing for scoliosis: a prospective study of the Sforzesco versus Lyon brace. Eura Medicophys 2007, 43(2):171-181, discussion 183-174.

152. Negrini S, Grivas TB: Introduction to the "Scoliosis" Journal Brace Technology Thematic Series: increasing existing knowledge and promoting future developments. Scoliosis 5(1):2.

153. Grivas TB, Bountis A, Vrasami I, Bardakos NV: Brace technology thematic series: the dynamic derotation brace. Scoliosis 2010, 5:20.

154. Weiss HR: "Brace technology" thematic series-the Gensingen brace in the treatment of scoliosis. Scoliosis 5:22.

155. Weiss HR, Werkmann M: "Brace Technology" Thematic Series-The ScoliOlogiC(R) Cheneau light brace in the treatment of scoliosis. Scoliosis 5:19.

156. Katz DE, Durrani AA: Factors that influence outcome in bracing large curves in patients with adolescent idiopathic scoliosis. Spine 2001, 26(21):2354-2361.

157. Landauer F, Wimmer C, Behensky H: Estimating the final outcome of brace treatment for idiopathic thoracic scoliosis at 6-month follow-up. Pediatr Rehabil 2003, 6(3-4):201-207.

158. Upadhyay SS, Nelson IW, Ho EK, Hsu LC, Leong JC: New prognostic factors to predict the final outcome of brace treatment in adolescent idiopathic scoliosis. Spine 1995, 20(5):537-545.

159. Allington NJ, Bowen JR: Adolescent idiopathic scoliosis: treatment with the Wilmington brace. A comparison of full-time and part-time use. $J$ Bone Joint Surg Am 1996, 78(7):1056-1062.

160. Katz DE, Herring JA, Browne RH, Kelly DM, Birch JG: Brace wear control of curve progression in adolescent idiopathic scoliosis. J Bone Joint Surg Am 2010, 92(6):1343-1352.

161. Negrini S, Fusco C, Romano M, Zaina F, Atanasio S: Clinical and postural behaviour of scoliosis during daily brace weaning hours. Stud Health Technol Inform 2008, 140:303-306.

162. Seifert J, Selle A, Flieger C, Gunther KP: [Compliance as a prognostic factor in the treatment of idiopathic scoliosis]. Orthopade 2009, 38(2):151-158.

163. Rivett L, Rothberg A, Stewart A, Berkowitz R: The relationship between quality of life and compliance to a brace protocol in adolescents with idiopathic scoliosis: a comparative study. BMC Musculoskelet Disord 2009, 10:5.

164. Lindeman M, Behm K: Cognitive strategies and self-esteem as predictors of brace-wear noncompliance in patients with idiopathic scoliosis and kyphosis. J Pediatr Orthop 1999, 19(4):493-499.

165. Birbaumer N, Flor H, Cevey B, Dworkin B, Miller NE: Behavioral treatment of scoliosis and kyphosis. J Psychosom Res 1994, 38(6):623-628.

166. MacLean WE Jr, Green NE, Pierre CB, Ray DC: Stress and coping with scoliosis: psychological effects on adolescents and their families. J Pediatr Orthop 1989, 9(3):257-261.

167. Bunge EM, de Bekker-Grob EW, van Biezen FC, Essink-Bot ML, de Koning HJ: Patients' preferences for scoliosis brace treatment: a discrete choice experiment. Spine (Phila Pa 1976) 2010, 35(1):57-63.

168. DiRaimondo CV, Green NE: Brace-wear compliance in patients with adolescent idiopathic scoliosis. J Pediatr Orthop 1988, 8(2):143-146.

169. Morton A, Riddle R, Buchanan R, Katz D, Birch J: Accuracy in the prediction and estimation of adherence to bracewear before and during treatment of adolescent idiopathic scoliosis. J Pediatr Orthop 2008, 28(3):336-341. 
170. Helfenstein A, Lankes M, Ohlert K, Varoga D, Hahne HJ, Ulrich HW Hassenpflug J: The objective determination of compliance in treatment of adolescent idiopathic scoliosis with spinal orthoses. Spine (Phila Pa 1976) 2006, 31(3):339-344.

171. Havey R, Gavin T, Patwardhan A, Pawelczak S, Ibrahim K, Andersson GB, Lavender S: A reliable and accurate method for measuring orthosis wearing time. Spine (Phila Pa 1976) 2002, 27(2):211-214.

172. Lou E, Raso J, Hill D, Durdle N, Mahood J, Moreau M: Brace monitoring system for the treatment of scoliosis. Stud Health Technol Inform 2002, 88:218-221.

173. Takemitsu M, Bowen JR, Rahman T, Glutting JJ, Scott CB: Compliance monitoring of brace treatment for patients with idiopathic scoliosis. Spine 2004, 29(18):2070-2074, discussion 2074.

174. Vandal S, Rivard CH, Bradet R: Measuring the compliance behavior of adolescents wearing orthopedic braces. Issues Compr Pediatr Nurs 1999, 22(2-3):59-73.

175. Nicholson GP, Ferguson-Pell MW, Smith K, Edgar M, Morley T: The objective measurement of spinal orthosis use for the treatment of adolescent idiopathic scoliosis. Spine 2003, 28(19):2243-2250, discussion 2250-2241.

176. Rahman T, Bowen JR, Takemitsu M, Scott C: The association between brace compliance and outcome for patients with idiopathic scoliosis. J Pediatr Orthop 2005, 25(4):420-422.

177. Lou E, Hill D, Parent E, Raso J, Mahood J, Moreau M, Hedden D: Preliminary validation of curve progression model for brace treatment. Stud Health Technol Inform 2008, 140:294-298.

178. Negrini S: Bracing adolescent idiopathic scoliosis today. Disabil Rehabil Assist Technol 2008, 3(3):107-111.

179. Weiss HR, Rigo M: The cheneau concept of bracing-actual standards. Stud Health Technol Inform 2008, 135:291-302.

180. Weiss HR, Rigo M: Expert-driven Cheneau applications: Description and in-brace corrections. Physiother Theory Pract 2011, 27(1):61-67.

181. Noonan KJ, Weinstein SL, Jacobson WC, Dolan LA: Use of the Milwaukee brace for progressive idiopathic scoliosis. J Bone Joint Surg Am 1996, 78(4):557-567.

182. Spoonamore MJ, Dolan LA, Weinstein SL: Use of the Rosenberger brace in the treatment of progressive adolescent idiopathic scoliosis. Spine 2004, 29(13):1458-1464.

183. Clin J, Aubin CE, Sangole A, Labelle H, Parent S: Correlation between immediate in-brace correction and biomechanical effectiveness of brace treatment in adolescent idiopathic scoliosis. Spine (Phila Pa 1976) 2010, 35(18):1706-1713.

184. Lou E, Hill D, Raso J: Brace treatment for adolescent idiopathic scoliosis. Stud Health Technol Inform 2008, 135:265-273.

185. Emans JB, Kaelin A, Bancel P, Hall JE, Miller ME: The Boston bracing system for idiopathic scoliosis. Follow-up results in 295 patients. Spine 1986, 11(8):792-801.

186. Kessler J: Efficacy of a new computer-aided design/computer-aided manufacture orthosis in the treatment of adolescent idiopathic scoliosis. J Pediatr Orthop B 2008, 17(4):207-211.

187. Sankar WN, Albrektson J, Lerman L, Tolo VT, Skaggs DL: Scoliosis in-brace curve correction and patient preference of CAD/CAM versus plaster molded TLSOs. J Child Orthop 2007, 1(6):345-349.

188. Weiss HR, Werkmann M, Stephan C: The ScoliOlogiC "Cheneau light" brace-does the reduction of material affect the desired correction? Stud Health Technol Inform 2006, 123:250-254.

189. Wong MS, Cheng JC, Lo KH: A comparison of treatment effectiveness between the CAD/CAM method and the manual method for managing adolescent idiopathic scoliosis. Prosthet Orthot Int 2005, 29(1):105-111.

190. Castro FP Jr: Adolescent idiopathic scoliosis, bracing, and the HueterVolkmann principle. Spine J 2003, 3(3):180-185.

191. Beausejour M, Petit Y, Grimard G, Aubin CE, Dansereau J, Labelle H: Relationships between strap tension, interface pressures and spine correction in brace treatment of scoliosis. Stud Health Technol Inform 2002, 88:207-211.

192. Perie D, Aubin CE, Lacroix M, Lafon Y, Labelle H: Biomechanical modelling of orthotic treatment of the scoliotic spine including a detailed representation of the brace-torso interface. Med Biol Eng Comput 2004, 42(3):339-344.

193. Tolo VT, Gillespie R: The characteristics of juvenile idiopathic scoliosis and results of its treatment. J Bone Joint Surg Br 1978, 60-B(2):181-188.
194. Figueiredo UM, James Jl: Juvenile idiopathic scoliosis. J Bone Joint Surg Br 1981, 63-B(1):61-66.

195. Mannherz RE, Betz RR, Clancy M, Steel HH: Juvenile idiopathic scoliosis followed to skeletal maturity. Spine (Phila Pa 1976) 1988, 13(10):1087-1090.

196. McMaster MJ: Infantile idiopathic scoliosis: can it be prevented? J Bone Joint Surg Br 1983, 65(5):612-617.

197. Kahanovitz N, Levine DB, Lardone J: The part-time Milwaukee brace treatment of juvenile idiopathic scoliosis. Long-term follow-up. Clin Orthop Relat Res 1982, 167: 145-151.

198. Fusco C, Zaina F, Negrini S: End-growth results in juvenile idiopathic scoliosis treated with conservative approach. Scoliosis 2010, 5(Suppl 1): 071.

199. Smith JR, Samdani AF, Pahys J, Ranade A, Asghar J, Cahill P, Betz RR: The role of bracing, casting, and vertical expandable prosthetic titanium rib for the treatment of infantile idiopathic scoliosis: a single-institution experience with 31 consecutive patients. Clinical article. J Neurosurg Spine 2009, 11(1):3-8.

200. Goldberg CJ, Gillic I, Connaughton O, Moore DP, Fogarty EE, Canny GJ, Dowling FE: Respiratory function and cosmesis at maturity in infantileonset scoliosis. Spine 2003, 28(20):2397-2406.

201. Mener G, Rigault P, Pouliquen JC, Tanguy D: [Results of the orthopedic treatment of scoliosis in children under 7 years of age. Apropos of 75 cases]. Rev Chir Orthop Reparatrice Appar Mot 1986, 72(5):355-366.

202. Sanders JO, D'Astous J, Fitzgerald M, Khoury JG, Kishan S, Sturm PF: Derotational casting for progressive infantile scoliosis. J Pediatr Orthop 2009, 29(6):581-587.

203. McMaster MJ, Macnicol MF: The management of progressive infantile idiopathic scoliosis. J Bone Joint Surg Br 1979, 61(1):36-42.

204. James Jl: The management of infants with scoliosis. J Bone Joint Surg $\mathrm{Br}$ 1975, 57(4):422-429.

205. Bergoin M: [Treatment of idiopathic scoliosis in children]. Ann Pediatr (Paris) 1993, 40(4):259-269.

206. Negrini S, Atanasio S, Fusco C, Zaina F: Efficacy of bracing immediately after the end of growth: final results of a retrospective case series. Scoliosis 2009, 4(Suppl 2):049.

207. Wong MS, Cheng JC, Wong MW, So SF: A work study of the CAD/CAM method and conventional manual method in the fabrication of spinal orthoses for patients with adolescent idiopathic scoliosis. Prosthet Orthot Int 2005, 29(1):93-104.

208. Perie D, Aubin CE, Petit Y, Labelle H, Dansereau J: Personalized biomechanical simulations of orthotic treatment in idiopathic scoliosis. Clin Biomech (Bristol, Avon) 2004, 19(2):190-195.

209. Perie D, Aubin CE, Petit Y, Beausejour M, Dansereau J, Labelle H: Boston Brace correction in idiopathic scoliosis: a biomechanical study. Spine 2003, 28(15):1672-1677.

210. Gignac D, Aubin CE, Dansereau J, Labelle H: Optimization method for 3D bracing correction of scoliosis using a finite element model. Eur Spine J 2000, 9(3):185-190.

211. Poncet $\mathrm{P}$, Dansereau J, Labelle H: Geometric torsion in idiopathic scoliosis: three-dimensional analysis and proposal for a new classification. Spine 2001, 26(20):2235-2243.

212. Zaina F, Negrini S, Atanasio S, Fusco C, Romano M, Negrini A: Specific exercises performed in the period of brace weaning can avoid loss of correction in Adolescent Idiopathic Scoliosis (AIS) patients: Winner of SOSORT's 2008 Award for Best Clinical Paper. Scoliosis 2009, 4(1):8.

213. Weiss H, Negrini S, Hawes M, Rigo M, Kotwicki T, Grivas T, SOSORT Mamot: Physical Exercises in the Treatment of Idiopathic Scoliosis at Risk of brace treatment-SOSORT Consensus paper 2005. Scoliosis 2005.

214. Romano M, Minozzi S, Bettany-Saltikov J, Zaina F, Chockalingam N, Weiss HR, Maier-Hennes A, Negrini S: Exercises for adolescent idiopathic scoliosis. Cochrane Database of Systematic Reviews 2009, , 2: CD007837.

215. Wan L, Wang G-x, Bian R: Exercise therapy in treatment of essential Sshaped scoliosis: evaluation of Cobb angle in breast and lumbar segment through a follow-up of half a year. Zhongguo Linchuang Kangfu (Chinese Journal of Clinical Rehabilitation) 2005, 9(34):82-84.

216. Negrini S, Zaina F, Romano M, Negrini A, Parzini S: Specific exercises reduce brace prescription in adolescent idiopathic scoliosis: A prospective controlled cohort study with worst-case analysis. J Rehabil Med 2008, 40(6):451-455. 
217. Hawes MC: The use of exercises in the treatment of scoliosis: an evidence-based critical review of the literature. Pediatr Rehabil 2003, 6(34):171-182.

218. Hawes MC: The use of exercises in the treatment of scoliosis. An evidence-based critical review of the literature. 4th International Conference on Conservative Management of Spinal Deformities: 2007 Boston: SOSORT (Society on Scoliosis Orthopaedic and Rehabilitation Treatment); 2007

219. Sponseller PD: Bracing for adolescent idiopathic scoliosis in practice today. J Pediatr Orthop 2011, 31(1 Suppl):S53-60.

220. Schiller JR, Thakur NA, Eberson CP: Brace management in adolescent idiopathic scoliosis. Clin Orthop Relat Res 2010, 468(3):670-678.

221. Stone B, Beekman C, Hall V, Guess V, Brooks HL: The effect of an exercise program on change in curve in adolescents with minimal idiopathic scoliosis. A preliminary study. Phys Ther 1979, 59(6):759-763.

222. Focarile FA, Bonaldi A, Giarolo MA, Ferrari U, Zilioli E, Ottaviani C: Effectiveness of nonsurgical treatment for idiopathic scoliosis. Overview of available evidence. Spine 1991, 16(4):395-401.

223. Fusco C, Zaina F, Atanasio S, Romano M, Negrini A, Negrini S: Physical exercises in the treatment of adolescent idiopathic scoliosis: an updated systematic review. Physiother Theory Pract 2011, 27(1):80-114

224. Negrini S, Antonini G, Carabalona R, Minozzi S: Physical exercises as a treatment for adolescent idiopathic scoliosis. A systematic review. Pediatr Rehabil 2003, 6(3-4):227-235.

225. Negrini S, Fusco C, Minozzi S, Atanasio S, Zaina F, Romano M: Exercises reduce the progression rate of adolescent idiopathic scoliosis: results of a comprehensive systematic review of the literature. Disabil Rehabil 2008, 30(10):772-785.

226. Lenssinck ML, Frijlink AC, Berger MY, Bierman-Zeinstra SM, Verkerk K Verhagen AP: Effect of bracing and other conservative interventions in the treatment of idiopathic scoliosis in adolescents: a systematic review of clinical trials. Phys Ther 2005, 85(12):1329-1339.

227. Negrini S, Romano M: On "effect of bracing..." Lenssinck et al Phys Ther 2005:85:1329-1339. Phys Ther 2007, 87(1):112, author reply 112-113.

228. Weiss HR, Weiss G, Petermann F: Incidence of curvature progression in idiopathic scoliosis patients treated with scoliosis in-patient rehabilitation (SIR): an age- and sex-matched controlled study. Pediatr Rehabil 2003, 6(1):23-30.

229. Mollon G, Rodot J: Scolioses structurales mineures et kinèsitherapie. Etude statistique compareative des rèsultas. Kinesithérapie scientifique 1986, , 244: 47-56

230. Ducongè $P$ : La rèèducation de la scoliose. Mythè ou rèalitè? Rèsonance Europeennes Du Rachis 2002, 10: 1229-1236.

231. Klisic P, Nikolic Z: Scoliotic attitudes and idiopathic scoliosis. In Proceedings of the International Congress on Prevention of Scoliosis in Schoolchildren. Volume 1. Milan: Edizioni Pro-Juventute; 1985:91-92.

232. Negrini S, Negrini A, Romano M, Verzini N, Parzini S: A controlled prospective study on the efficacy of SEAS.02 exercises in preventing progression and bracing in mild idiopathic scoliosis. Stud Health Technol Inform 2006, 123:523-526.

233. Negrini S, Negrini A, Romano M, Verzini N, Parzini S: A controlled prospective study on the efficacy of SEAS.02 exercises in preparation to bracing for idiopathic scoliosis. Stud Health Technol Inform 2006, 123:519-522.

234. Ferraro C, Masiero S, Venturin A: Effect of esercise therapy on mild idiopathic scoliosis. Europa Medicophysica 1998, , 34: 25-31.

235. Durmala J, Dobosiewicz K, Kotwicki T, Jendrzejek H: Influence of asymmetric mobilisation of the trunk on the Cobb angle and rotation in idiopathic scoliosisin children and adolescents. Ortop Traumatol Rehab 2003, 5(1):80-85

236. den Boer WA, Anderson PG, v Limbeek J, Kooijman MA: Treatment of idiopathic scoliosis with side-shift therapy: an initial comparison with a brace treatment historical cohort. Eur Spine J 1999, 8(5):406-410.

237. Weiss HR, Lohschmidt K, el-Obeidi N, Verres C: Preliminary results and worst-case analysis of in patient scoliosis rehabilitation. Pediatr Rehabil 1997, 1(1):35-40

238. Otman S, Kose N, Yakut Y: The efficacy of Schroth s 3-dimensional exercise therapy in the treatment of adolescent idiopathic scoliosis in Turkey. Saudi Med J 2005, 26(9):1429-1435.
239. Mamyama T, Kitagawal T, Takeshita K, Nakainura K: Side shift exercise for idiopathic scoliosis after skeletal maturity. Stud Health Technol Inform 2002, 91:361-364.

240. Mooney V, Gulick J, Pozos R: A preliminary report on the effect of measured strength training in adolescent idiopathic scoliosis. J Spinal Disord 2000, 13(2):102-107.

241. Mclntire K, Asher M, Burton D, Liu W: Trunk rotational strength training for the management of adolescent idiopathic scoliosis (AIS). Stud Health Technol Inform 2006, 123:273-280.

242. Weiss HR: Influence of an in-patient exercise program on scoliotic curve. Ital J Orthop Traumatol 1992, 18(3):395-406.

243. Maruyama T, Matsushita T, Takeshita K, Kitagawa K, Nakamura K, Kurokawa T: Side shift exercises for idiopathic scoliosis after skeletal maturity. J Bone and Joint Surgery (Br) 2003, 85 B(Suppl. 1).

244. Rigo M, Quera-Salva G, Puigdevall N: Effect of the exclusive employment of physiotherapy in patients with idiopathic scoliosis. Proceedings Book of the 11th International Congress of the World Confederation for Physical Therapy. London 1991, 3:1319-1321.

245. Weiss H, Weiss G, Petermann F: Incidence of curvature progression in idiopathic scoliosis patients treated with scoliosis in-patient rehabilitation (SIR): an age- and sex-matched cotrolled study. Pediatric Rehabilitation 2003, 6:23-30

246. Soucacos P, Zacharis K, Soultanis K, Gelalis J, Kalos N, Beris A, Xenakis T, Johnson E: Assessment of curve progression in Idiopathic Scoliosis. European Spine Journal 1998, 7:270-277.

247. Bunnell WP: The natural history of idiopathic scoliosis before skeletal maturity. Spine 1986, 11(8):773-776.

248. Lonstein JE: Natural history and school screening for scoliosis. Orthop Clin North Am 1988, 19(2):227-237.

249. Weinstein S: Natural history. Spine 1999, 24:2592-2600.

250. Negrini S, Carabalona R: Social acceptability of treatments for adolescent idiopathic scoliosis: a cross-sectional study. Scoliosis 2006, 1:14.

251. Neugebauer H: [Active scoliosis in a modified Milwaukee brace (author's transl)]. Z Orthop Ihre Grenzgeb 1977, 115(3):391-396.

252. Blount WP, Schmidt A: The Milwaukee brace in the treatment of scoliosis J Bone Joint Surg 1957, 37:693.

253. Blount W, Moe J: The Milwaukee Brace. Baltimore: The William and Wilkins Company; 1973.

254. Watts HG, Hall JE, Stanish W: The Boston Brace system for the treatment of low thoracic and lumbar scoliosis by the use of a girdle without superstructure. Clin Orthop Relat Res 1977, , 126: 87-92.

255. Stagnara P: Les deformations du rachis. Paris: Expansion Scientifique Francaise; 1976.

256. Stagnara P, Mollon G, De Mauroy J: Reeducation des scolioses. Paris: Expansion Scientifique Francaise; 1990

257. Biel T, Bach-Otho I, Kovermann S: [Functional treatment of idiopathic scoliosis in the Cheneau corset. Exercise therapy guidelines for patients]. Fortschr Med 1983, 101(29):1335-1339.

258. Cheneau J: Das Cheneau-Korsett. Ein Handbuch. Dortmund: Orthopadie Technik; 19931.

259. Cheneau J: Corset-Cheneau. Manuel d'Orthopèdie des scolioses suivant la technique originale. Paris: Frison Roche; 19941.

260. Negrini S: Approach to scoliosis changed due to causes other than evidence: patients call for conservative (rehabilitation) experts to join in team orthopedic surgeons. Disabil Rehabil 2008, 30(10):731-741.

261. Maruyama T, Takeshita K, Kitagawa T: Side-shift exercise and hitch exercise. Stud Health Technol Inform 2008, 135:246-249.

262. Wong MS, Evans JH: Biomechanical evaluation of the Milwaukee brace. Prosthet Orthot Int 1998, 22(1):54-67.

263. Rigo M, Quera-Salva G, Puigdevall N, Martinez M: Retrospective results in immature idiopathic scoliotic patients treated with a Cheneau brace. Stud Health Technol Inform 2002, 88:241-245.

264. Rigo M, Reiter C, Weiss H: Effect of conservative management on the prevalence of surgery in patients with adolescent idiopathic scoliosis. Pediatric Rehabilitation 2003, 6:209-214.

265. Weiss HR, Maier-Hennes A: Specific exercises in the treatment of scoliosis-differential indication. Stud Health Technol Inform 2008, 135:173-190.

266. Negrini S, Atanasio S, Fzaina F, Romano M: Rehabilitation of adolescent idiopathic scoliosis: results of exercises and bracing from a series of 
clinical studies. Europa Medicophysica-SIMFER 2007 Award Winner. Eur J Phys Rehabil Med 2008, 44(2):169-176.

267. Weiss HR, Weiss G: Meta Analysis of Prevalence of Surgery in Patients with Scoliosis Following Conservative Treatment. International Research Society on Spinal Deformities: 2004; Vancouver 2004, 416-419.

268. Weiss H, Weiss G: Meta Analysis of Prevalence of Surgery in Patients with Scoliosis Following Conservative Treatment. International Research on Spinal Deformities; Vancouver 2004, 416-419.

269. Dickson RA, Leatherman KD: Cotrel traction, exercises, casting in the treatment of idiopathic scoliosis. A pilot study and prospective randomized controlled clinical trial. Acta Orthop Scand 1978, 49(1):46-48.

270. Miyasaki RA: Immediate influence of the thoracic flexion exercise on vertebral position in Milwaukee brace wearers. Phys Ther 1980, 60(8):1005-1009

271. Carman D, Roach JW, Speck G, Wenger DR, Herring JA: Role of exercises in the Milwaukee brace treatment of scoliosis. J Pediatr Orthop 1985, 5(1):65-68

272. Smania N, Picelli A, Romano M, Negrini S: Neurophysiological basis of rehabilitation of adolescent idiopathic scoliosis. Disabil Rehabil 2008, 30(10):763-771.

273. Mollon G: Kinesitérapie des scolioses. Encycl Med Chir $26300 A 1046071990$.

274. Stoboy H, Speierer B: [Pulmonary function tests and spiroergometric parameters during rehabilitation of patients with idiopathic scoliosis (fusion of the spine with Harrington rod and training) (author's transl)]. Arch Orthop Unfallchir 1975, 81(3):247-254

275. Rubery PT, Bradford DS: Athletic activity after spine surgery in children and adolescents: results of a survey. Spine (Phila Pa 1976) 2002, 27(4):423-427.

276. Weiss HR: Rehabilitation of scoliosis patients with pain after surgery. Stud Health Technol Inform 2002, 88:250-253.

277. Lewis C, Erhard R, Drysdale G: Kyphoscoliosis improvement while treating a patient for adhesive capsulitis using the active therapeutic movement version 2. J Manipulative Physiol Ther 2008, 31(9):715-722.

278. Chen KC, Chiu EH: Adolescent idiopathic scoliosis treated by spinal manipulation: a case study. J Altern Complement Med 2008, 14(6):749-751

279. Aspegren DD, Cox JM: Correction of progressive idiopathic scoliosis utilizing neuromuscular stimulation and manipulation: a case report. J Manipulative Physiol Ther 1987, 10(4):147-156.

280. Hawes MC, Brooks WJ: Reversal of the signs and symptoms of moderately severe idiopathic scoliosis in response to physical methods. Stud Health Technol Inform 2002, 91:365-368.

281. Hawes MC, Brooks WJ: Improved chest expansion in idiopathic scoliosis after intensive, multiple-modality, nonsurgical treatment in an adult. Chest 2001, 120(2):672-674.

282. Morningstar MW, Woggon D, Lawrence G: Scoliosis treatment using a combination of manipulative and rehabilitative therapy: a retrospective case series. BMC Musculoskelet Disord 2004, 5:32

283. Romano M, Negrini S: Manual therapy as a conservative treatment for adolescent idiopathic scoliosis: a systematic review. Scoliosis 2008, 3:2.

284. Martinez-Llorens J, Ramirez M, Colomina MJ, Bago J, Molina A, Caceres E, Gea J: Muscle dysfunction and exercise limitation in adolescent idiopathic scoliosis. Eur Respir J 2010, 36(2):393-400.

285. Leong JC, Lu WW, Luk KD, Karlberg EM: Kinematics of the chest cage and spine during breathing in healthy individuals and in patients with adolescent idiopathic scoliosis. Spine 1999, 24(13):1310-1315.

286. Lisboa C, Moreno R, Fava M, Ferretti R, Cruz E: Inspiratory muscle function in patients with severe kyphoscoliosis. Am Rev Respir Dis 1985, 132(1):48-52.

287. Kotani T, Minami S, Takahashi K, Isobe K, Nakata Y, Takaso M, Inoue M, Maruta T, Akazawa T, Ueda T, et al: An analysis of chest wall and diaphragm motions in patients with idiopathic scoliosis using dynamic breathing MRI. Spine 2004, 29(3):298-302.

288. Kotani T, Minami S, Takahashi K, Isobe K, Nakata Y, Takaso M, Inoue M, Nishikawa S, Maruta T, Tamaki T, et al: Three dimensional analysis of chest wall motion during breathing in healthy individuals and patients with scoliosis using an ultrasonography-based system. Stud Health Technol Inform 2002, 91:135-139.

289. Smyth RJ, Chapman KR, Wright TA, Crawford JS, Rebuck AS: Ventilatory patterns during hypoxia, hypercapnia, and exercise in adolescents with mild scoliosis. Pediatrics 1986, 77(5):692-697.
290. Estenne M, Derom E, De Troyer A: Neck and abdominal muscle activity in patients with severe thoracic scoliosis. Am J Respir Crit Care Med 1998, 158(2):452-457.

291. Kafer ER: Idiopathic scoliosis. Mechanical properties of the respiratory system and the ventilatory response to carbon dioxide. J Clin Invest 1975, 55(6):1153-1163.

292. Takahashi S, Suzuki N, Asazuma T, Kono K, Ono T, Toyama Y: Factors of thoracic cage deformity that affect pulmonary function in adolescent idiopathic thoracic scoliosis. Spine (Phila Pa 1976) 2007, 32(1):106-112

293. Padua S, Aulisa L, Fieri C, Ciappi G, Di Marzo A: Valutazione dei valori polmonari in scoliosi idiopatiche dorsali e rapporti con la rotazione vertebrale prima e dopo l'iintervento di artrodesi. Progressi in Patologie Vertebrali 1979, 11:81-91.

294. Piazzini DB, Aulisa AG: Alterazioni della meccanica respiratoria nella scoliosi idiopatica. Eura Medicophys 2003, 39:291-293.

295. Giordano A, Fuso L, Galli M, Calcagni ML, Aulisa L, Pagliari G, Pistelli R: Evaluation of pulmonary ventilation and diaphragmatic movement in idiopathic scoliosis using radioaerosol ventilation scintigraphy. Nucl Med Commun 1997, 18(2):105-111.

296. Barrios C, Perez-Encinas C, Maruenda JI, Laguia M: Significant ventilatory functional restriction in adolescents with mild or moderate scoliosis during maximal exercise tolerance test. Spine 2005, 30(14):1610-1615.

297. Kesten S, Garfinkel SK, Wright T, Rebuck AS: Impaired exercise capacity in adults with moderate scoliosis. Chest 1991, 99(3):663-666.

298. DiRocco PJ, Breed AL, Carlin JI, Reddan WG: Physical work capacity in adolescent patients with mild idiopathic scoliosis. Arch Phys Med Rehabil 1983, 64(10):476-478

299. Hawes MC: Scoliosis and the human spine. Tucson, Arizona, USA: West Press; Second 2003.

300. Pehrsson K, Bake B, Larsson S, Nachemson A: Lung function in adult idiopathic scoliosis: a 20 year follow up. Thorax 1991, 46(7):474-478.

301. Pehrsson K, Nachemson A, Olofson J, Strom K, Larsson S: Respiratory failure in scoliosis and other thoracic deformities. A survey of patients with home oxygen or ventilator therapy in Sweden. Spine 1992, 17(6):714-718.

302. Vercauteren M, Van Beneden M, Verplaetse R, Croene P, Uyttendaele D, Verdonk R: Trunk asymmetries in a Belgian school population. Spine (Phila Pa 1976) 1982, 7(6):555-562.

303. Shneerson JM, Madgwick R: The effect of physical training on exercise ability in adolescent idiopathic scoliosis. Acta Orthop Scand 1979, 50(3):303-306.

304. Shneerson JM: Cardiac and respiratory responses to exercise in adolescent idiopathic scoliosis. Thorax 1980, 35(5):347-350.

305. Weiss HR, Negrini S, Hawes MC, Rigo M, Kotwicki T, Grivas TB, Maruyama T: Physical exercises in the treatment of idiopathic scoliosis at risk of brace treatment-SOSORT consensus paper 2005. Scoliosis 2006, 1:6.

306. Weiss HR: The effect of an exercise program on vital capacity and rib mobility in patients with idiopathic scoliosis. Spine 1991, 16(1):88-93

307. Weiss H, Bickert W: Improvement of the parameters of right-heart stress evidenced by electrocardiographic examinations by the in-patient rehabilitation program according to Schroth in adult patients with scoliosis. Orthop Prax 1996, 32:450-453.

308. Fuschillo S, De Felice A, Gaudiosi C, Balzano G: Nocturnal mechanical ventilation improves exercise capacity in kyphoscoliotic patients with respiratory impairment. Monaldi Arch Chest Dis 2003, 59(4):281-286.

309. Buyse B, Meersseman W, Demedts M: Treatment of chronic respiratory failure in kyphoscoliosis: oxygen or ventilation? Eur Respir J 2003, 22(3):525-528.

310. Nauffal D, Domenech R, Martinez Garcia MA, Compte L, Macian V Perpina M: Noninvasive positive pressure home ventilation in restrictive disorders: outcome and impact on health-related quality of life. Respir Med 2002, 96(10):777-783.

311. Margonato V, Fronte F, Rainero G, Merati G, Veicsteinas A: Effects of short term cast wearing on respiratory and cardiac responses to submaximal and maximal exercise in adolescents with idiopathic scoliosis. Eura Medicophys 2005, 41(2):135-140.

312. Korovessis P, Filos KS, Georgopoulos D: Long-term alterations of respiratory function in adolescents wearing a brace for idiopathic scoliosis. Spine 1996, 21(17):1979-1984.

313. Refsum HE, Naess-Andresen CF, Lange JE: Pulmonary function and gas exchange at rest and exercise in adolescent girls with mild idiopathic 
scoliosis during treatment with Boston thoracic brace. Spine 1990 15(5):420-423.

314. Kennedy JD, Robertson CF, Hudson I, Phelan PD: Effect of bracing on respiratory mechanics in mild idiopathic scoliosis. Thorax 1989, 44(7):548-553.

315. Sevastikoglou JA, Linderholm $H$, Lindgren U: Effect of the Milwaukee brace on vital and ventilatory capacity of scoliotic patients. Acta Orthop Scand 1976, 47(5):540-545.

316. Athanasopoulos S, Paxinos T, Tsafantakis E, Zachariou K, Chatziconstantinou S: The effect of aerobic training in girls with idiopathic scoliosis. Scand J Med Sci Sports 1999, 9(1):36-40.

317. Kenanidis E, Potoupnis ME, Papavasiliou KA, Sayegh FE, Kapetanos GA: Adolescent idiopathic scoliosis and exercising: is there truly a liaison? Spine 2008, 33(20):2160-2165.

318. Negrini S, Kenanidis E, Potoupnis ME, Papavasiliou KA, et al: Adolescent idiopathic scoliosis and exercising: is there truly a liaison? Spine 2008;33:2160-5. Spine 2009, 34(4):419, author reply 419-420.

319. Hawes MC, O'Brien J P: The transformation of spinal curvature into spinal deformity: pathological processes and implications for treatment. Scoliosis 2006, 1(1):3.

320. Fallstrom K, Cochran T, Nachemson A: Long-term effects on personality development in patients with adolescent idiopathic scoliosis. Influence of type of treatment. Spine 1986, 11(7):756-758.

321. Meyer C, Haumont T, Gauchard GC, Leheup B, Lascombes P, Perrin PP: The practice of physical and sporting activity in teenagers with idiopathic scoliosis is related to the curve type. Scand J Med Sci Sports 2008, 18(6):751-755.

322. Meyer C, Cammarata E, Haumont T, Deviterne D, Gauchard GC, Leheup B, Lascombes P, Perrin PP: Why do idiopathic scoliosis patients participate more in gymnastics? Scand J Med Sci Sports 2006, 16(4):231-236.

323. Tanchev PI, Dzherov AD, Parushev AD, Dikov DM, Todorov MB: Scoliosis in rhythmic gymnasts. Spine 2000, 25(11):1367-1372.

324. Warren MP, Brooks-Gunn J, Hamilton LH, Warren LF, Hamilton WG: Scoliosis and fractures in young ballet dancers. Relation to delayed menarche and secondary amenorrhea. N Engl J Med 1986, 314(21):1348-1353.

325. Burwell RG, Dangerfield PH: The NOTOM hypothesis for idiopathic scoliosis: is it nullified by the delayed puberty of female rhythmic gymnasts and ballet dancers with scoliosis? Stud Health Technol Inform 2002, 91:12-14

326. Potoupnis ME, Kenanidis E, Papavasiliou KA, Kapetanos GA: The role of exercising in a pair of female monozygotic (high-class athletes) twins discordant for adolescent idiopathic scoliosis. Spine (Phila Pa 1976) 2008, 33(17):E607-610

327. Becker TJ: Scoliosis in swimmers. Clin Sports Med 1986, 5(1):149-158.

328. Parsch D, Gartner V, Brocai DR, Carstens C, Schmitt H: Sports activity of patients with idiopathic scoliosis at long-term follow-up. Clin J Sport Med 2002, 12(2):95-98.

329. Kotwicki T, Negrini S, Grivas TB, Rigo M, Maruyama T, Durmala J, Zaina F: Methodology of evaluation of morphology of the spine and the trunk in idiopathic scoliosis and other spinal deformities-6th SOSORT consensus paper. Scoliosis 2009, 4:26.

330. Cote P, Kreitz BG, Cassidy JD, Dzus AK, Martel J: A study of the diagnostic accuracy and reliability of the Scoliometer and Adam's forward bend test. Spine (Phila Pa 1976) 1998, 23(7):796-802, discussion 803.

331. Berg AO: Screening for adolescent idiopathic scoliosis: a report from the United States Preventive Services Task Force. J Am Board Fam Pract 1993, 6(5):497-501.

332. Bunnell WP: Outcome of spinal screening. Spine 1993, 18(12):1572-1580.

333. Bunnell WP: An objective criterion for scoliosis screening. J Bone Joint Surg Am 1984, 66(9):1381-1387.

334. Grosso C, Negrini S, Boniolo A, Negrini AA: The validity of clinical examination in adolescent spinal deformities. Stud Health Technol Inform 2002, 91:123-125.

335. De Wilde L, Plasschaert F, Cattoir H, Uyttendaele D: Examination of the back using the Bunnell scoliometer in a Belgian school population around puberty. Acta Orthop Belg 1998, 64(2):136-143.

336. Ferraro C, Gottardo A: La misurazione del gibbo: studio critico mediante un dispositivo tascabile. Minerva Ortop Traumatol 1993, 44:637-643.

337. Agostini S, Taglialavoro G, Fabris D, Mammano S, Ferraro C: Relationship between rib hump deformity and vertebral rotation in idiopathic scoliosis. Ital J Orthop Traumatol 1983, 9(3):387-395.
338. D'Osualdo F, Schierano S, lannis M, Righini E: The level protractor: a new simple instrument to measure Cobb angle and back hump. A validation study. Eura Medicophys 2000, 36:191-196.

339. Bago J, Sanchez-Raya J, Perez-Grueso FJ, Climent JM: The Trunk Appearance Perception Scale (TAPS): a new tool to evaluate subjective impression of trunk deformity in patients with idiopathic scoliosis. Scoliosis 2010, 5:6.

340. Bago J, Climent JM, Pineda S, Gilperez C: Further evaluation of the Walter Reed Visual Assessment Scale: correlation with curve pattern and radiological deformity. Scoliosis 2007, 2:12.

341. Pineda S, Bago J, Gilperez C, Climent JM: Validity of the Walter Reed Visual Assessment Scale to measure subjective perception of spine deformity in patients with idiopathic scoliosis. Scoliosis 2006, 1:18.

342. Sanders JO, Polly DW Jr, Cats-Baril W, Jones J, Lenke LG, O'Brien MF, Stephens Richards B, Sucato DJ: Analysis of patient and parent assessment of deformity in idiopathic scoliosis using the walter reed visual assessment scale. Spine 2003, 28(18):2158-2163.

343. Asher M, Min Lai S, Burton D, Manna B: Discrimination validity of the scoliosis research society-22 patient questionnaire: relationship to idiopathic scoliosis curve pattern and curve size. Spine 2003, 28(1):74-78.

344. Asher M, Min Lai S, Burton D, Manna B: Scoliosis research society-22 patient questionnaire: responsiveness to change associated with surgical treatment. Spine 2003, 28(1):70-73.

345. Asher M, Min Lai S, Burton D, Manna B: The reliability and concurrent validity of the scoliosis research society-22 patient questionnaire for idiopathic scoliosis. Spine 2003, 28(1):63-69.

346. Asher M, Lai SM, Burton D, Manna B: Trunk deformity correction stability following posterior instrumentation and arthrodesis for idiopathic scoliosis. Stud Health Technol Inform 2002, 91:469-472.

347. Aulisa AG, Guzzanti V, Perisano C, Marzetti E, Specchia A, Galli M, Giordano M, Aulisa L: Determination of quality of life in adolescents with idiopathic scoliosis subjected to conservative treatment. Scoliosis 2011, 5:21.

348. Vasiliadis E, Grivas TB: Quality of life after conservative treatment of adolescent idiopathic scoliosis. Stud Health Technol Inform 2008, 135:409-413.

349. Vasiliadis E, Grivas TB, Savvidou O, Triantafyllopoulos G: The influence of brace on quality of life of adolescents with idiopathic scoliosis. Stud Health Technol Inform 2006, 123:352-356.

350. Vasiliadis E, Grivas TB, Gkoltsiou K: Development and preliminary validation of Brace Questionnaire (BrQ): a new instrument for measuring quality of life of brace treated scoliotics. Scoliosis 2006, 1:7.

351. Kotwicki T, Kinel E, Stryla W, Szulc A: Estimation of the stress related to conservative scoliosis therapy: an analysis based on BSSQ questionnaires. Scoliosis 2007, 2:1

352. Weiss HR, Werkmann M, Stephan C: Brace related stress in scoliosis patients-Comparison of different concepts of bracing. Scoliosis 2007, 2:10.

353. Weiss HR, Reichel D, Schanz J, Zimmermann-Gudd S: Deformity related stress in adolescents with AIS. Stud Health Technol Inform 2006, 123:347-351.

354. Botens-Helmus C, Klein R, Stephan C: The reliability of the Bad Sobernheim Stress Questionnaire (BSSQbrace) in adolescents with scoliosis during brace treatment. Scoliosis 2006, 1:22.

355. Zaina F, Atanasio S, Negrini S: Clinical evaluation of scoliosis during growth: description and reliability. Stud Health Technol Inform 2008, 135:125-138.

356. D'Osualdo F, Schierano S, lannis M: Validation of clinical measurement of kyphosis with a simple instrument, the arcometer. Spine 1997, 22(4):408-413.

357. Zaina F, Atanasio S, Ferraro C, Fusco C, Negrini A, Romano M, Negrini S: Review of rehabilitation and orthopedic conservative approach to sagittal plane diseases during growth: hyperkyphosis, junctional kyphosis, and Scheuermann disease. Eur J Phys Rehabil Med 2009, 45(4):595-603.

358. Negrini S, Negrini A, Santambrogio GC, Sibilla P: Relation Between Static Angles of the Spine and a Dynamic Event Like Posture: Approach to the Problem. In Three Dimensional Analysis of Spinal Deformities. Volume 1. Edited by: D'Amico M, Merolli A, Santambrogio GC. Amsterdam: IOS PressOhmsha; 1995:209-214 
359. Beauchamp M, Labelle H, Grimard G, Stanciu C, Poitras B, Dansereau J: Diurnal variation of Cobb angle measurement in adolescent idiopathic scoliosis. Spine 1993, 18(12):1581-1583.

360. Omeroglu $\mathrm{H}$, Ozekin O, Bicimoglu A: Measurement of vertebral rotation in idiopathic scoliosis using the Perdriolle torsionmeter: a clinical study on intraobserver and interobserver error. Eur Spine J 1996, 5(3):167-171.

361. Weiss HR: Measurement of vertebral rotation: Perdriolle versus Raimondi. Eur Spine J 1995, 4(1):34-38.

362. Mehta MH: The rib-vertebra angle in the early diagnosis between resolving and progressive infantile scoliosis. J Bone Joint Surg Br 1972, 54(2):230-243.

363. McAlindon RJ, Kruse RW: Measurement of rib vertebral angle difference. Intraobserver error and interobserver variation. Spine 1997, 22(2):198-199.

364. Horton WC, Brown CW, Bridwell KH, Glassman SD, Suk SI, Cha CW: Is there an optimal patient stance for obtaining a lateral $36^{\prime \prime}$ radiograph? A critical comparison of three techniques. Spine (Phila Pa 1976) 2005, 30(4):427-433.

365. Negrini S: Focus on flexed posture and hyperkyphosis: prevention and rehabilitation to reduce disability and increase quality of life. Eur J Phys Rehabil Med 2009, 45(4):567-569.

366. Marks M, Stanford C, Newton P: Which lateral radiographic positioning technique provides the most reliable and functional representation of a patient's sagittal balance? Spine (Phila Pa 1976) 2009, 34(9):949-954.

367. Kotwicki T: Evaluation of scoliosis today: Examination, X-rays and beyond. Disabil Rehabil 2008, 30(10):742-751.

368. Weiss HR, Elobeidi N: Comparison of the kyphosis angle evaluated by video rasterstereography (VRS) with x-ray measurements. Stud Health Technol Inform 2008, 140:137-139.

369. Risser J: The iliac apophysis. An invaluable sign in the management of scoliosis. Clin Orthop Relat Res 1958, 11:111-119.

370. Hoppenfeld S, Lonner B, Murthy V, Gu Y: The rib epiphysis and other growth centers as indicators of the end of spinal growth. Spine 2004, 29(1):47-50.

371. Kotwicki T: Improved accuracy in Risser sign grading with lateral spinal radiography. Eur Spine J 2008, 17(12):1676-1685.

372. Shuren N, Kasser JR, Emans JB, Rand F: Reevaluation of the use of the Risser sign in idiopathic scoliosis. Spine (Phila Pa 1976) 1992, 17(3):359-361.

373. Malfair D, Flemming AK, Dvorak MF, Munk PL, Vertinsky AT, Heran MK, Graeb DA: Radiographic evaluation of scoliosis: review. AJR Am J Roentgenol 2010, 194(3 Suppl):S8-22.

374. Sucato DJ: Management of severe spinal deformity: scoliosis and kyphosis. Spine (Phila Pa 1976) 2010, 35(25):2186-2192.

375. Jones SJ: What is the evidence justifying non-invasive SEP and MEP monitoring during spinal surgery? Supp/ Clin Neurophysiol 2006, 59:305-310.

376. Fernandez AA, Guerrero Al, Martinez MI, Vazquez ME, Fernandez JB, Chesa i Octavio E, Labrado Jde L, Silva ME, de Araoz MF, Garcia-Ramos R, et al: Malformations of the craniocervical junction (Chiari type I and syringomyelia: classification, diagnosis and treatment). BMC Musculoskelet Disord 2009, 10(Suppl 1):S1.

377. Grivas TB, Wade MH, Negrini S, O'Brien JP, Maruyama T, Hawes MC, Rigo M, Weiss HR, Kotwicki T, Vasiliadis ES, et al: SOSORT consensus paper: school screening for scoliosis: Where are we today? Scoliosis 2007, 2(1):17.

378. Appraisal of Guidelines for Research \& Evaluation (AGREE) Instrument. [http://www.agreetrust.org/].

379. de Mauroy J, Weiss H, Aulisa A, Aulisa L, Brox J, Durmala J, Fusco C, Grivas T, Hermus J, Kotwicki T, et al: 7th SOSORT consensus paper: conservative treatment of idiopathic \& Scheuermann's kyphosis. Scoliosis 2010, 5:9.

380. Weiss HR: Scoliosis: a journal dedicated to multidisciplinary research on prevention, control, and treatment of scoliosis and other spinal deformities. Scoliosis 2006, 1(1):1.

doi:10.1186/1748-7161-7-3

Cite this article as: Negrini et al:: 2011 SOSORT guidelines: Orthopaedic and Rehabilitation treatment of idiopathic scoliosis during growth. Scoliosis 2012 7:3.

\section{Submit your next manuscript to BioMed Central and take full advantage of:}

- Convenient online submission

- Thorough peer review

- No space constraints or color figure charges

- Immediate publication on acceptance

- Inclusion in PubMed, CAS, Scopus and Google Scholar

- Research which is freely available for redistribution

Submit your manuscript at www.biomedcentral.com/submit 